\title{
Evaluation and outcome measures in the treatment of female urinary stress incontinence: International Urogynecological Association (IUGA) guidelines for research and clinical practice
}

\author{
G. Ghoniem • E. Stanford - K. Kenton • C. Achtari • \\ R. Goldberg • T. Mascarenhas • M. Parekh • \\ K. Tamussino $\cdot$ S. Tosson $\cdot$ G. Lose $\cdot$ E. Petri
}

Received: 30 August 2007 / Accepted: 14 October 2007 / Published online: 17 November 2007

(C) International Urogynecology Journal 2007

\section{Introduction}

\section{Gamal Ghoniem}

\section{Background}

Millions of women are afflicted with stress urinary incontinence (SUI) and pelvic organ prolapse (POP) around the globe, and the literature is abundant with different types of surgery to correct these problems. Only recently have outcome measures been applied to research in these areas. There are great variations in types of surgery performed,

\section{G. Ghoniem $(\bowtie)$}

Cleveland Clinic Florida,

Weston, FL, USA

e-mail: ghonieg@ccf.org

\section{E. Stanford}

Center for Advanced Pelvic Surgery,

Belleville, IL, USA

K. Kenton

Loyola University Medical Center Maywood,

Maywood, IL, USA

C. Achtari

Maternité, CHUV,

Lausanne, Switzerland

R. Goldberg

Evanston, IL, USA

T. Mascarenhas

Hospital S. João,

Porto, Portugal secondary to many factors such as surgeon's training and socioeconomic factors. As the population of aging women increases worldwide, it is inevitable that these women's disorders will become more prevalent. This will pose a major challenge to the health care systems.

\section{Objectives}

The field exploring and treating pelvic floor disorders is evolving rapidly, and guidelines should be developed and updated every few years so that the most recent evidencebased medicine is incorporated.

M. Parekh

Geisinger Medical Center,

Danville, PA, USA

K. Tamussino

Medical University of Graz,

Graz, Austria

S. Tosson

University Hospital of Hartlepool,

Hartlepool, UK

G. Lose

Glostrup Hospital,

Glostrup, Denmark

E. Petri

Acad.Teaching Hospital University of Rostock,

Schwerin, Germany 
Based on our meeting at the IUGA/ICS Joint Meeting in Paris (August 2004), the IUGA Research and Development Committee (RDC) developed the following steps to accomplish the objectives:

1- Review recent English literature

2- Review outcome measures (primary and secondary)

3- Prepare recommendations

4- Define and consult expert opinions

5- Write a white paper to circulate among members utilizing the IUGA web site

6- Final revision after feedback from members

7- Publish in IUJ

In a subsequent meeting during the IUGA Annual Meeting in Copenhagen (August, 2005), the outlines of the work were discussed, revised, and divided among the members.

Index case

The index case is that of an otherwise healthy female with stress urinary incontinence with or without pelvic organ prolapse.

\section{Materials and methods}

A combination of a systematic review of literature (MEDLINE $^{\circledR}$ ), Cochrane database, ICI (International Consultation on Incontinence) recommendations, and expert opinion, including history, physical examination, questionnaires, tests, surgical treatment, outcome measures, and follow-up were evaluated and categorized into:

- Recommended

- Optional

- Not recommended

\section{Methods of review}

The methodological quality and appropriateness of selected studies and data extraction rested solely on the judgment of each author, reviewed by experts, and subsequently made available for review by the IUGA membership. The outcomes were evaluated into primary and secondary measures by the RDC.

Primary

Initial clinical evaluation

Voiding diary

Stress testing

Grading of SUI and Pad testing

Quality of life measures
Urethral mobility

Patient satisfaction

Prolapse assessment

\section{Initial clinical evaluation}

\section{Gamal Ghoniem}

\section{Clinical assessment}

Assessment of patient expectation, and social and economical factors are important in choosing treatment. Lifestyle adjustment, behavioral modifications, and dietary management may benefit some patients.

\section{History}

General history, including drug, obstetrical, surgical, bowel and neurological evaluation should be part of the exam. The type of incontinence determined from taking the history, whether stress, urge, or mixed, is used to direct treatment. There is low correlation between urodynamic findings and symptoms of urge incontinence. However, women with pure stress incontinence symptoms are also unlikely to have detrusor overactivity on urodynamics [1].

\section{Physical examination}

Genitourinary examination should include determination of estrogenic status of the vagina, caliber, description of interstitial or vaginal masses, and neurological examination. Sensation and bulbo-cavernosus reflex should be checked.

\section{Pelvic floor muscle evaluation}

Pelvic floor muscle (PFM) evaluation can be performed by instructing a woman in PFM contraction, with measure and documenting of PFM contraction at initial evaluation and throughout treatment. Various tests measure different aspects of PFM function. Although ultrasound and magnetic resonance imaging (MRI) are more objective measurements of PFM, vaginal palpation is standard when assessing the ability to contract the PFM. Further research is required to determine reliability and validity scores for imaging techniques [2].

\section{Urinalysis}

Urodynamic testing

Neurophysiological testing

Surgical complications

Cost effectiveness
Urinary tract infection (UTI) is an easily treatable cause of lower urinary tract symptoms (LUTS). Urine dipstick has low sensitivity and high specificity to detect UTI. While a 
negative test indicates no UTI, a positive one correlates with a positive culture in only one third of cases [3].

Urinalysis by dipstick is highly recommended in all patients with incontinence Urine cultures (mid-stream) should be performed in asymptomatic women with positive dipstick and symptomatic women with negative dipstick.

Microscopic urinanalysis is recommended for patients with microhematuria Urine cytology is indicated for patients with proven microhematuria and undergoing the work-up to exclude urinary neoplasm.

\section{Residual urine}

Residual urine may be measured by either a catheter or ultrasound. There is a good clinical correlation between the two methods [4]. The latter is non-invasive and can be used when catheterization is not required. There is no consensus as to the definition of large or high (abnormal) residual volume values. Residual urine volumes should be determined in any woman with symptoms of voiding dysfunction, or with a history of recurrent UTIs.

\section{Cystoscopy}

Bladder lesions are found in less than $2 \%$ of patients with incontinence; therefore, cystoscopy should not be performed routinely in patients with stress urinary incontinence to exclude neoplasm [5]. It is recommended in patients with irritative bladder symptoms in the absence of infection. Cystoscopy is highly recommended for the evaluation of patients with hematuria, which may be indicative of bladder tumor. It is highly recommended for urinary fistulae, including vesicovaginal and ureterovaginal, and any suspected extra-urethral source of urinary incontinence.

Cystoscopy is recommended when a reversible cause is not found, in patients with pyuria or irritative voiding symptoms, such as frequency, urgency, and urge incontinence. It is recommended in patients with bladder pain and LUTS; in recurrent cystitis; and in patients with suburethral mass [6].

\section{Blood tests}

Standard metabolic evaluation of renal function with measurement of serum creatinine and blood urea levels is recommended when renal impairment is suspected.

\section{Imaging}

Imaging is not routinely recommended. It is indicated when upper urinary tract pathology is suspected. Specific indications include neurogenic bladder, chronic high-grade pelvic organ prolapse, low compliance of the bladder, or high residual urine volumes.

\section{Voiding diary}

\section{Gamal Ghoniem}

\section{Introduction}

The voiding diary is a record of micturition behavior completed by the patient. It is among the best possible means of obtaining objective data on subjective symptoms [7]. The International Continence Society (ICS) recommends the inclusion of voiding diaries in the clinical assessment of patients with LUTS [8]. There are various terms used for voiding diaries, including micturition time or frequency charts, frequency volume charts, and bladder or urinary diaries. Recently, computerized voiding diaries have been developed. A drawback of the computerized diary may be a fear of technology, which is common in certain patient populations such as the elderly [9]. Maintaining a voiding diary involves patients in the management of their condition, and helps them become an active partner in the treatment process. Moreover, it provides them with an objective assessment of their condition both during and after treatment. Objective data (diary) does not necessarily correlate with the degree of bother from incontinence (e.g., urge incontinence); each is a different aspect of evaluation. It can be difficult for the patient to recall or judge voiding frequency and pattern retrospectively, especially when voiding behavior is irregular [10]. Bother depends on recall, while a voiding diary is objective. McCormack et al. [11] revealed poor agreement between subjectively estimated urinary frequency and urinary frequency shown on a chart. The diary also provides an evaluation of treatment, which is more accurate than the history because patients sometimes claim improvement, presumably to please their doctors, when their diaries in fact show no change. However, the diary is only supplemental to the patient's history, and both should be used to identify the complaint and formulate an accurate diagnosis.

There are a number of different types of voiding diaries, including a Frequency Chart, which is the simplest type of voiding diary because the patient is asked to record only micturition and incontinence episodes. A frequency-volume chart requires the patient to record the 
amount of urine of each micturition, the time of each void, and incontinence episodes [12]. Other parameters include the number of pads used and estimated fluid intake in cups or mugs.

Urgency may be recorded as $0,+$, or ++ , or on a scale from $0-10$, depending on the diary used. Urgency can also be evaluated in minutes [13], by asking the patient to estimate how long he or she could wait before voiding.

\section{Diary duration}

It has been shown that a complex long-term diary decreases patient compliance with recording. A 3-day diary is long enough to be reliable, and short enough to decrease patient burden and increase compliance [14]. Nygaard and Holcomb reported good correlation of 0.887 between the first 3 days of a 7-day diary and the last 4 days [15]. They suggest that the 3-day diary is an appropriate outcome measure for clinical trials, evaluating treatment of SUI.

\section{Voiding diaries and patient history}

The voiding diary represents a self-monitoring daily record of the patient's voiding behavior, whereas the history is based on the patient's recall, which is greatly affected by the patient's degree of bother. Patients are sometimes surprised at the actual number of voiding events that occur once they are asked to record them.

\section{Using voiding diaries in incontinent patients}

The primary use of voiding diaries in incontinent patients is documentation of incontinence episodes. Diaries may provide clues to the underlying cause of incontinence, particularly if the diary includes patient comments about the reason(s) or condition(s) associated with the incontinence episodes. Voiding diaries can be used in evaluation of the severity of urinary incontinence, as the patient may report the number of incontinent episodes, number of pads used, and the amount of leakage.

The diagnostic role of the diary can be limited. Utilizing the voiding diary in patients with and without urge incontinence, one study showed significant differences between groups in frequency, mean voided volume, and largest single voided volume, although the overlap was large [16]. A similar study compared women with stress urinary incontinence to a normal group, and surprisingly showed that total voided volume, frequency of micturition, and largest single voided volume were all significantly higher in the genuine urinary stress incontinence group than in the normal group [17].

The voiding diary has been used to differentiate between urge and stress incontinence [18]. Most of these studies have shown not only significant differences between populations with urge and stress incontinence, but also considerable overlap. Total voided volumes, mean voided volumes, and largest single voided volumes were less in urge incontinent than stress urinary incontinent groups. Frequency of micturition during the day and at night was more in the urge than in the stress incontinent groups. Analysis of one of these studies showed that the frequency of micturition at night was the single parameter that best discriminates the two conditions. Combining daytime micturition frequency with the largest single voided volume or the mean voided volume increased the discrimination power [18].

It is reasonable to evaluate incontinent patients with a voiding diary before other more invasive tests such as urodynamic investigation because it is a simple, noninvasive, and inexpensive tool. It evaluates the patient over a longer period of time, away from the laboratory. If urodynamic studies are indicated, a voiding diary can help the clinician choose which studies should be performed. A voiding diary is also reliable and valid when measuring the symptoms of overactive bladder, including urge and urge incontinence episodes, and nocturia [19].

\section{Assessment of voiding dysfunction treatment}

In addition to providing baseline measurements before treatment, voiding diaries can be used to evaluate the progress and efficacy of treatment. Recently, new medications for treatment of LUTS, including overactive bladder, have been evaluated in clinical trials. All of these medications are directed at symptom improvement; therefore, patient-completed voiding diaries are commonly used in evaluation of the effectiveness of these drugs [20,21]. This application also explains the recent increase in the number of published studies utilizing the voiding diary.

Voiding diaries can be used to evaluate treatment modalities other than pharmacotherapy, such as surgery and behavioral therapy. For example, they can provide a baseline assessment before anti-incontinence surgery and evaluate outcome after the procedure. With behavioral therapy, changes and improvement occur gradually due to learning and the time it takes to strengthen muscles. These gradual changes are often unnoticed by the patient, but are measured and documented objectively in the diary. Objective feedback about such small changes can help the patient maintain the motivation and persistence needed for a successful outcome. 


\section{Research and asymptomatic populations}

Voiding diaries have been used to define normal urinary measurements and physiological differences between normal populations. Most of the published data on urinary diaries have been obtained in women. Several studies established normal values for healthy females [22-23]. Data obtained from frequency-volume charts of normal females showed that mean voided volume was 230 to $250 \mathrm{ml}$, mean frequency was 5.7 to 7.3 , and total voided volume was 1,272 to $1,350 \mathrm{ml}$. Two of these studies analyzed diurnal and nocturnal data separately $[24,25]$. This may be important, because nighttime diuresis may exceed daytime diuresis and may be responsible for nocturia, especially in the elderly.

Fitzgerald et al. [26] studied urinary habits with voiding diaries in asymptomatic women and reported that diary variables are affected by age, race, and fluid intake. Voids per liter intake varied with age and were higher among parous and Asian women. The number of nighttime voids depended only on patient age. The mean and maximum voided volumes were lower among black women.

\section{Conclusions and recommendations}

The voiding diary is highly recommended in clinical research and optional in the clinical practice of female urinary incontinence. The 3-day diary is practical, has a high patient acceptance and compliance, and it correlates well with the 7-day diary.

\section{Stress test}

\section{Teresa Mascarenhas}

\section{Introduction}

Several studies have demonstrated that the diagnosis of a specific type of incontinence based on a simple history and physical examination is extremely unreliable, and clinical decisions regarding treatment should be based on specialized testing [27].

The techniques for the evaluation of the incontinent patient range in complexity from a simple cough stress test to video fluorourodynamics [28]. In a cost-conscious society, having a test that is easy to perform, inexpensive, and also diagnostically reliable would be of great value to physicians managing women with urinary incontinence.

The cough stress test can be performed with the bladder empty or with the patient's bladder filled up to $300 \mathrm{ml}$ or to subjective fullness [27], and then, while in an upright or lithotomy position, having the patient perform a series of forceful coughs. The external urethral meatus is observed during the coughs for gross urine loss. If urine loss is noted, the test is positive with a diagnosis of stress urinary incontinence. The cough stress test has been compared with other sophisticated testing methods (multichannel urodynamics studies) and has demonstrated good sensitivity and specificity in the diagnosis of genuine stress incontinence [28-30]. However, the reproducibility of the results of this technique need to be demonstrated to gain widespread application, which includes establishing the reliability and validity of the test. Reliability means the ability of the test to be consistent and stable, i.e., reproducible.

A few clinical trials and studies have been conducted and published on the evaluation of the reliability of the cough stress test as a diagnostic test. This test is widely used as part of the clinician's physical examination of the patient for both diagnosis and also as an outcome measure after treatment. The test is mainly used in conjunction with other urodynamic testing; thus, it is difficult to evaluate its reliability in comparison with more sophisticated and expensive testing methods such as multichannel urodynamics.

The parameters normally used by most authors to characterize the reliability of the cough stress test include sensitivity, specificity, positive predictive value, and negative predictive value [31-35]. Sensitivity and specificity are the most common parameters for the comparison of clinical tests [32], being independent of the prevalence of the disease in the study population. Scotti and Myers [29] have shown that simple cystometry combined with a cough stress test is highly reliable in making the diagnosis of genuine stress incontinence. Wall et al. [30] have shown that bladder filling without pressure measurement, combined with a cough stress test is a simple, inexpensive, and reliable way of selecting patients with urge incontinence related to detrusor overactivity from those patients with straightforward stress urinary incontinence. According to Swift and Ostergard [28], the cough stress remains a highly specific test, particularly when combined with a prior negative cystometrogram.

\section{Description of the cough test}

If stress urinary incontinence is suspected, a provocative stress testing with direct visualization can be performed. The patient is asked to relax and cough vigorously while the examiner observes for urine loss from the urethra [36]. Optimally, this test should be performed when the patient's bladder is full. The stress test, also known as cough stress test [37] or provocative stress test [36], is a simple test that involves filling a patient's bladder to at least $300 \mathrm{ml}$ or 
symptomatic fullness. Bladder filling for stress testing may be performed conveniently in conjunction with catheterization for post-void residual (PVR) measurement [36]. A noncatheterized cough test can be performed after instructing the patient to urinate $2 \mathrm{~h}$ before the test, followed by drinking two cups of water (16 oz). The bladder volume is checked with the bladder scan, and if the volume is between 250 and $300 \mathrm{cc}$, the test is performed. The patient is asked to cough while standing, usually on a blue towel, with her legs apart (or in the supine position if she is unable to stand), and the physician directly visualizes the urethral meatus. If urine leaks from the external urethral meatus, the result is a positive cough stress test. If the test is initially performed in the supine position and no leakage is observed, then the test is repeated in the standing position [36]. It has been observed that some patients do not cough forcibly in the laboratory setting and may consciously hold in during the test; thus, it is important that the patient relax before being asked to cough vigorously [36].

The cough stress test can also be performed with the bladder empty, known as the supine empty stress test (SEST). Generally, the patient voids first before the pelvic examination and is asked to cough or perform a Valsalva maneuver while in the lithotomy position. If the patient loses urine, she has a positive SEST [37]. Using maximal urethral closure pressure to diagnose ISD, Lobel and Sand [33] reported that the SEST had 65 to $70 \%$ sensitivity and 67 to $76 \%$ specificity for predicting ISD. Interpretation of the results after testing for urinary incontinence can be summarized in the Table $1[36,37]$.

Using abdominal leak point pressure (ALPP) to define ISD, McLennan and Bent [31] reported that SEST had 79\% sensitivity and $63 \%$ specificity. Conversely, Hsu et al. [32] reported that the SEST had 93.5\% sensitivity, 90\% specificity, $96.7 \%$ positive predictive value, and $81.8 \%$ negative predictive value for detecting ISD. The residual urine volume at the time of the test does not significantly affect the diagnostic accuracy of SEST for the prediction of low Valsalva leak point pressure (VLPP) [34]. The overall sensitivity and positive predictive value of the SEST, regardless of the residual volume, is insufficient to make a diagnosis of low VLPP without multichannel urodynamics. The standardization principle used by Hsu et al. [32], to perform the supine stress test and bladder filling to $200 \mathrm{ml}$,

Table 1 Results after testing for urinary incontinence

\begin{tabular}{ll}
\hline Test & Result \\
\hline No leakage with cough stress test & Negative \\
Instantaneous leakage with cough stress test & Positive \\
Leakage in spurts on cough stress test & Positive (mixed) \\
Delayed leakage with flow & Detrusor overactivity \\
Leakage with empty bladder, supine position & ISD [5, 10] \\
\hline
\end{tabular}

avoids potential confounding factors such as significant PVR, use of diuretics, or presence of polydipsia noted in other studies.

\section{Clinical use}

Some published studies seem to indicate that performing a cough stress test before filling the bladder can be unreliable and may miss $80 \%$ of the cases of stress incontinence, but when performed at a bladder volume of $300 \mathrm{ml}$ or symptomatic fullness, the test is highly reliable [27, 29, 37]. A positive cough stress indicates a good correlation with the presence of stress urinary incontinence; however, if uninhibited detrusor contractions are noted during a cystometrogram, preceding the cough stress test, the results become suspect [27, 35, 37], and the diagnosis of stress incontinence should be confirmed by multichannel studies [28]. A negative cough stress test rules out most cases of stress incontinence [35]. If a cough stress test with bladder filling is used more frequently in the initial evaluation of incontinent women, some authors believe that practitioners, with limited access to sophisticated urodynamic studies, will be able to select patients for further testing in a more informed way [30]. Thus, the available evidence demonstrates that the cough stress test can be a useful and reliable tool in the diagnosis of SUI. However, for a more complete evaluation, it must be used in conjunction with other urodynamic testing, particularly if detrusor overactivity is suspected. The cystometrogram and cough stress test are not essential for a basic evaluation, particularly if a conservative therapy is contemplated; however, if a more invasive treatment is needed, these tests should be performed [37].

The diagnostic accuracy of the SEST was found to be poor for prediction or exclusion of low maximum urethral closure pressure [31,33]; however, this test has been shown to have a negative predictive value of $90 \%$ for ruling out a low VLPP in a referral population [31]. Thus, this simple test has been recommended as a means for the urogynecologic surgeon to be reasonably assured that ISD is not present, without performing multichannel urodynamics before stress incontinence surgery [31, 33, 34].

Lobel and Sand [33] performed the SEST at a variable interval up to $20 \mathrm{~min}$ after bladder catheterization. Conversely, McLennan and Bent [31] performed the SEST without uniformly catheterizing patients to ensure bladder emptiness. It is noteworthy to find that data on patient age, parity, prior gynecological surgery, and prior incontinence surgery did not significantly improve the predictive value of the supine stress test for ISD [32].

The SEST is easy to perform, inexpensive, and without significant risk. A positive SEST in combination with a fixed urethra is diagnostic for ISD. In low prevalence populations, 
a negative test reliably excludes the presence of ISD. However, for high prevalence and referral populations, the low predictive values of the test limit its usefulness.

\section{Conclusions and recommendations}

The cough stress test, according to a body of evidence consisting of randomized controlled trials, appears to be a reliable and simple test for the diagnosis of stress urinary incontinence. It should be viewed only as a screening test requiring further evaluation with more sophisticated urodynamic tests. The supine empty stress test is the most reliable non-urodynamic predictor of ISD. The cough stress test is recommended for both clinical research and practice. The empty supine stress test is optional for both.

\section{Incontinence severity and evaluation}

\section{Mitesh H. Parekh, Karl Tamussino}

\section{Severity of incontinence}

It is often useful, both in a clinical setting or for research purposes, to make an assessment of the severity of incontinence. In a clinical setting, assessing severity helps to determine which patients need care and to evaluate the effectiveness of care rendered. In a research setting, we need reliable instruments that will accurately differentiate change in incontinence severity to evaluate and compare treatments. Different instruments have been described to assess the severity of incontinence. These instruments can be classified into subjective or objective measures and further divided by whether they are validated instruments or not.

\section{Subjective measures}

Not validated

A voiding diary is the simplest method utilized to quantify urine loss. The period recorded in a voiding diary varies. A 1week diary has been shown to reliably assess the frequency and estimated amount of urine loss [38]. Elser et al. [39] found a significant correlation between the number of incontinence episodes recorded in the diary and patient history. For obvious reasons, it can be a subjective and crude method. As described in the previous chapter on Voiding diaries, the 3-day diary correlates well with the 7-day diary and is recommended for use in clinical research and practice.

Visual analog graded scale responses, such as the $10-\mathrm{cm}$ analog scales, have been used. Frazer et al. [40] found that such scales correlated poorly with more standardized measures such as the 2-h pad test.

Stamey's incontinence scoring system (Table 2) is based on the patient's incontinence history alone and is similar to a classification used earlier by Ingelman-Sundberg [41]. It has not been validated but is simple and has been used frequently in research to measure outcome, especially with injectable bulking agents.

Various methods of estimating severity of leakage based on questions related to frequency and amount of leakage have been described [42]. Other authors have estimated severity of leakage based on activity restriction, extra laundry, pad usage, and wet clothes [43, 44]. None of the above methods were validated, nor were they objective due to multiple biases that may interfere with the assessment.

Validated

The Urogenital Distress Inventory (UDI) for Women [45] is a symptom inventory instrument for assessing disease severity. A validated short form correlates well with the long form and is also available for use in practice (see chapter on QOL measures)[46].

The Severity Index for Urinary Incontinence in Women $[47,48]$ is a simple severity index for urinary incontinence in women (Table 3). It can be used to initially evaluate a patient and to monitor the response to interventions.

The index value obtained by multiplying the total amounts in the two parameters is further characterized into a severity index of three or four levels. The score range is then a minimum score of 0 to a maximum score of 8 (or 12 for the fourth level). The higher the score, the more severe the urinary incontinence. Sandvik's index is a valid representation of severity as measured by the pad weighing test [48].

The Leakage Index for Women with Urinary Stress Incontinence is a five-point scale containing 13 types of exertions [49]. The leakage index was found to be reproducible, but a limitation is its design for use in women with stress incontinence only.

\section{Objective measures: pad testing}

Pad testing denotes a validated methodology to quantify urine loss by measuring the weight gain of absorbent pads during a test period [50]. Pad testing can quantify urine loss

Table 2 Stamey's incontinence scoring system

\begin{tabular}{ll}
\hline Grade 0 & No incontinence \\
Grade 1 & Incontinence with coughing or straining \\
Grade 2 & Incontinence with change in position or walking \\
Grade 3 & Total incontinence at all times \\
\hline
\end{tabular}


Table 3 Severity index for urinary incontinence in women [47, 48]

\begin{tabular}{lll}
\hline Parameter & Finding & Points \\
\hline $\begin{array}{l}\text { How often is urine leakage } \\
\text { experienced? }\end{array}$ & $\begin{array}{l}\text { Never } \\
\text { Less than once a } \\
\text { month }\end{array}$ & 1 \\
& $\begin{array}{l}1 \text { to several } \\
\text { times a month }\end{array}$ & 2 \\
& $\begin{array}{l}1 \text { to several } \\
\text { times a week }\end{array}$ & 3 \\
& $\begin{array}{l}\text { Every day and/or } \\
\text { night }\end{array}$ & 4 \\
& A few drops & 1 \\
& A little & 2 \\
How much urine lost each time? & More & 3 \\
& & \\
$\begin{array}{l}\text { Severity index }=(\text { points for frequency) } \times \\
\text { (points for amount) }\end{array}$ & & \\
$1-2=$ slight, 3-6 $=$ moderate, $8-9=$ & & \\
severe, $12=$ very severe & & \\
\hline
\end{tabular}

but provides no clue as to the mechanism underlying the urine loss. Many pad tests have been described. Short-term $(<1,1,2 \mathrm{~h})$ and long-term ( $24 \mathrm{~h}$ and longer) tests have been used. Short-term tests are done in the office setting; longer tests are done by the patient in her daily environment. The International Continence Society (ICS) endorsed a 1-h pad test [51], which was however subsequently shown to have poor interdepartmental correlation and to be highly dependent on bladder volume [50].

Longer duration pad tests seem to be more reliable and accurate [52], but patient adherence and tolerance will be better in shorter tests; they are obviously cheaper and easier to conduct. In at least one study, the 1-h test had nearly $100 \%$ correlation with a 12 -h test. There are also other studies that show reproducibility and reliability of the 1-h test. The ICS has standardized the 1-h test for research purposes, as with longer tests, the investigator has no control over the test [38]. The ICI recommends a 20-min to 1-h test at standard bladder volume or 24-h at-home test, and it rates the level of evidence at 3 and grade of recommendation at $\mathrm{C}$ for both [53]. The 1-h test will have a higher false negative rate when leakage is mild or when patients are having $\mathrm{OAB}$ wet, which cannot be reproduced reliably during the 1 -h test.

Pad tests can quantify urine loss with a fair degree of reliability but provide no information on the mechanism underlying leakage

- 1 -h pad testing

- Not very accurate unless a fixed bladder volume is used

- Set exercises during the test improve test-retest reliability, sequence of tests has little effect on test results

- A pad weight gain $\geq 1$ g suggests a positive 1 -h test
- $\quad$-24-h pad testing

- Not standardized

- Correlates well with symptoms of incontinence

- A 24-h test has good reproducibility but poorer compliance than a 1 -h test

- A pad weight gain $\geq 1.3 \mathrm{~g}=$ positive 24 - $\mathrm{h}$ test (The upper limit of normal increase in pad weight varies according to the characteristics of the pad used. Highly absorbent pads will weigh up to $5 \mathrm{~g}$ )

- A test lasting longer than $24 \mathrm{~h}$ has little advantage.

Many studies on incontinence use higher values for pad weight test, depending on the type and characteristics of the pad. In a 1-h test, more than $2 \mathrm{~g}$ was used, and in the 24-h test, more than $8 \mathrm{~g}$ are indicators for incontinence.

\section{Conclusions and recommendations}

Pad tests have the advantage of directly measuring the amount of urine loss. They are inexpensive, noninvasive, and quite simple. As they do require active participation of patients for a prolonged period, accuracy may come at the cost of non-adherence. Many versions of pad tests are available; a longer version might be more useful in a research setting to increase the accuracy, and the short version, such as the standardized 1-h ICS pad, is test more practical. Sandvik's severity index may be an acceptable alternative to pad testing, especially in large epidemiological studies where pad testing might be cumbersome.

Pad testing is recommended for clinical studies, and optional in practice. Both 1 and 24-h pad tests are suitable for stress urinary incontinence. The 1-h pad test is not recommended for urge incontinence. Measurement of incontinence severity is recommended for research and optional in clinical practice.

\section{Quality of life measures}

\section{Roger Goldberg}

A basic challenge in studying and treating prolapse and incontinence lies in the largely subjective nature of these conditions. Their true impact is not solely based on discriminate variables but rather on the composite effect of numerous factors on a patient's overall lifestyle. For instance, daily voiding episodes or pad weight may not reveal the full impact of a therapeutic intervention on a patient's ability to resume, and enjoy, a normal routine. Focus groups have demonstrated that clinicians and patients may indeed view the impact of incontinence on quality of life differently, with 
patients focusing more on emotional well-being and disruption of routine activities [54]. When considered alone, neither urodynamic parameters nor symptom severity can reliably predict the quality of life impact of incontinence [55]. In assessing surgical outcomes, urogynecologists should therefore recognize that changes to objective measures, such as incontinence episodes, may fail to reflect changes-for better or worse - to the patient's actual quality of life.

A number of validated health-related quality of life instruments, falling into two major categories-general and condition-specific - have emerged over the past several years.

\section{Health-related quality of life}

Health-related quality of life (HRQOL) is a composite health care outcome implying several subsets of function, often categorized into physical well-being, social function, mental health, societal role, and general health perception. HRQOL instruments are typically comprised of numerous patientcompleted questions, or items, arranged into several domains.

In evaluating the impact of urogynecologic conditions on HRQOL, it becomes clear that these disorders can negatively impact all QOL domains. Patients with incontinence suffer a constellation of symptoms often leaving them uncomfortable, embarrassed and socially withdrawn. Self-esteem and body image may be profoundly altered by wetness, skin irritation, and odor, or the need for absorbent products. One study found that incontinent women spend less time walking, communicating with friends and family, working for pay, and engaging in personal grooming and hygiene then similar continent women [56]. Indeed, for many individuals, incontinence may be viewed as a sign of one's lost independence and lack of self control. Furthermore, many patients begin to adopt alternative coping strategies which include restricting one's wardrobe to dark clothing to hide urine stains, avoidance of sexual intimacy, reduction of oral fluid intake, and bathroom "mapping" [57]. In the elderly, QOL implications can become even more profound as incontinence becomes a common reason underlying nursing home admission [58]. The U.S. Special Committee on Aging has identified incontinence as one of the top QOL issues affecting the elderly.

\section{Recommended tools}

Determining the "best" measure of QOL impact remains a work in progress, largely because urogynecological conditions are associated with variable effects on psychological, physical, and sexual health. Cultural differences may also markedly influence the degree of bother experienced and/or reported by individual patients. QOL questionnaires in this field vary substantially in their content and in their specificity for incontinence.

Most patient-completed questionnaires consist of several domains. Examples may include "role limitations", "social limitations", "physical limitations", "general health perception", "emotional impact", "sleep and energy", and effects on personal relationships. Differences between questionnaires include the degree of condition-specificity (i.e., targeting QOL issues relating to only incontinence, vs those applicable to multiple health conditions), the period of time the patient is asked to report on, and the population wherein the test was validated. Both general and conditionspecific HRQOL questionnaires may reveal important aspects of the patient's subjective experience before and after treatment. It is important to recognize that medical comorbidities may alter the scoring of both general and condition-specific questionnaires [59] and should be considered when comparing scores across populations.

\section{General instruments}

One disadvantage of nonspecific surveys is their limited ability to characterize impairments specific to incontinence or pelvic floor dysfunction and their limited sensitivity for detecting small to moderate differences in QOL stemming from pelvic and (LUTS).

SF-36 is the most common general HRQOL instrument, a self-administered tool organizing HRQOL into eight scales addressing physical function, social function, pain, emotional well-being, energy, general health perceptions, and role limitation due to physical and/or emotional problems [60]. Two subscales-physical and mentalmay also be separately totaled. Kutner, et al. [61] found the SF-36 performed acceptably among incontinent patients. The SF-36 has been used to demonstrate diminished quality of life across numerous domains (including physical function, role function, bodily pain, health perceptions, social functioning, and mental health) for subjects with both 'wet' and 'dry' OAB [62]. Because the SF-36 is not specific to incontinence, it is particularly well suited for making comparisons across conditions - in other words, comparing the relative QOL impact of incontinence to hypertension, diabetes, and other unrelated disease states [63]. A general survey such as SF-36 may also be successfully used for demonstrating HRQOL differences between continent and incontinent subjects. In one such study, Hagglund et al. [64] demonstrated that incontinent women reported significantly lower scores in all eight domains of the SF-36 and that urge had a greater impact than stress incontinence.

Oh, et al. compared the SF-36 to an incontinence-specific questionnaire in 109 stress incontinent women and 80 
controls and concluded that the generic instrument had poor sensitivity for estimating the incontinence impact on QOL (65). However, as already mentioned, in appropriate settings, they offer the flexibility of comparing the broad impact of prolapse, incontinence, or any other specific condition to unrelated medical states.

\section{Disease-specific instruments}

Several HRQOL questionnaires have been introduced in the urogynecologic community in recent years and are tailored specifically for women with urinary, colorectal, and sexual disorders, and become increasingly specific for detecting change within samples of women affected by those disorders. The majority of incontinence-specific QOL instruments are available in the public domain. Two of the most common are the Incontinence Impact Questionnaire (IIQ) and the Urogenital Distress Inventory (UDI), both of which were designed specifically for incontinence in the female population. Short-form versions (IIQ-7, UDI-6) of the original questionnaires are useful for clinical practice, where the original 53-item version may prove to be excessive. IIQ-7 and UDI-6 scores have been shown to significantly change after surgery for stress incontinence, and POP, with subjective continence after surgery, is associated with superior scores on both scales [66]. The IIQ and its short form (IIQ-7) have taken on increasing popularity in epidemiological surveys and clinical trials, more commonly used in the context of stress urinary incontinence but also providing a valid QOL instrument within urge-incontinent samples [67, 68].

The Pelvic Floor Distress Inventory (PFDI) and Pelvic Floor Impact Questionnaire (PFIQ) represent expanded modifications of the UDI and IIQ, respectively. They incorporate a broader array of pelvic floor questions. The PFDI assesses patient perception of distress relating to three clinical domains - urinary incontinence, colorectal dysfunction, and pelvic organ prolapse. The PFIQ estimates life impact across the same clinical domains. The sheer size of these questionnaires (PFDI 61 items, PFIQ 93 items) may reduce their utility within most clinical settings. Short-form versions of these surveys (PFDI-20 and PFIQ-7) were, as a result, recently introduced - and have been demonstrated to be valid and reliable in women with pelvic floor disorders [69].

The King's Health Questionnaire (KHQ) is a 21-item measure of HRQOL, designed for incontinent women [70]. The KHQ correlates reliably with the SF-36, it has been well established as reliable and valid among subjects with $\mathrm{OAB}$ [71], and it has been used to demonstrate subjective benefit among incontinent subjects receiving therapy [72, 73]. The KHQ has been translated into multiple languages.
Wren, et al. [74] established the reliability of a composite condition-specific QOL measure in women undergoing surgical treatment for pelvic organ prolapse and stress urinary incontinence, using a telephone-based QOL questionnaire. The questionnaire drew from several validated general and condition-specific HRQOL instruments (MESA, Hunskaar severity measure, PFDI, PFIQ, PISQ, SF-36 and LOT-R). Interviews were completed on 88 women, approximately 1 year after pelvic reconstructive surgery and then were repeated on each participant 2 weeks later to establish reliability of the telephone interview-based QOL assessment.

Other disease-specific instruments include the Symptom Severity Index (SSI) and Symptom Impact Index (SII). These short questionnaires (eight questions) were developed within a sample of women having stress incontinence surgery. There is little data to indicate their ability to respond to changes after therapeutic intervention.

\section{$\mathrm{OAB}$ and quality of life}

In measuring quality of life before and after pelvic reconstructive and incontinence surgery, one cannot overlook the potential role of OAB. Several studies have demonstrated that patients with urge incontinence report more emotional disturbance and lower HRQOL then patients with stress incontinence [75] and rate their need for medical attention as significantly higher [76]. According to the Social Function Questionnaire (SF-36), individuals with $\mathrm{OAB}$ demonstrate diminished capacity in most of the survey subsets addressing social and functional capabilities, even lower than other chronic diseases such as diabetes and hypertension [77]. Modified versions of the IIQ and UDI (the U-IIQ and U-UDI) have been developed to characterize the quality of life impact of frequency, urgency, and urge urinary incontinence, in more detailed fashion. To date, the only questionnaire specifically developed and validated for the evaluation of HRQOL in OAB patients (both "wet" and "dry") is the OAB-q [78, 79].

$\mathrm{OAB}$ and incontinence are also associated with adverse effects on sexual function [80]. In addition, and perhaps not surprisingly, $\mathrm{OAB}$ has been associated with depressionlikely due to the diminished self-esteem, feelings of helplessness or shame, social withdrawal, and reduction in physical fitness that accompany this disease [81, 82]. A study of 115 community-dwelling incontinent patients demonstrated that $60 \%$ suffering from urge incontinence had concurrent symptoms of depression according to the Beck Depression Inventory [83].

Other QOL instruments validated within incontinent populations, and applicable for the assessment of OAB, include the Incontinence Impact Questionnaire (IIQ) [45], 
Urge Impact Scale (URIS), I-QoL [84], and York Incontinence Perceptions Scale (YIPS) [85].

\section{Sexual dysfunction after surgery for SUI}

Reporting urinary incontinence to a health care professional by patients is difficult because of its stigma. Female sexual dysfunction (FSD), when co-existing with urinary incontinence, is usually not reported by patients and not explored by physicians. Barriers to screening for FSD exist, most commonly due to "lack of time" and unsatisfactory training with respect to FSD [86]. When sexually active women complete sexuality questionnaires, pelvic floor dysfunction (PFD) does not appear to independently affect sexual activity or satisfaction $(86,87)$. On the contrary, patients with UI may have a low sexual desire, related to a long history of stress urinary incontinence (SUI) and the fear of having an episode of urinary incontinence (UI) during intimacy, thus, resulting in sexual anxiety [88].

For patients with SUI who are going to be treated with surgery, coital UI after surgery for SUI was less acceptable than having postoperative frequent small leaks [89]. Because sexual activity and sexual satisfaction are very important aspects for patient's quality of life, and may be affected by surgical treatment of SUI, we have to consider both as an outcome measure of this surgery. Conflicting sexual function outcome results have been reported after SUI surgery. In general, most of the studies reported reduction in episodes of coital incontinence postoperatively with overall improved sexual function. Some studies found a few cases of postoperative "de novo" dyspareunia or anorgasmia [90, 91]. To evaluate if there is a sexual dysfunction, it is very important to have an instrument to measure the level of personal distress related to the sexual problems identified [92].

\section{How to measure the changes with surgical treatment of SUI}

A few studies have measured the changes in sexual life before and after surgery by validated questionnaires. The most frequently-used questionnaires in urogynecological patients have been the Female Sexual Function Index (FSFI) and the Pelvic Organ Prolapse/Urinary Incontinence Sexual Questionnaire (PISQ) specific for UI/POP (long or short form, PISQ-12). In published studies, which utilized these two questionnaires, the total score is better postoperatively, with improvements in both the physical and partner-related domains but no improvement in behavior emotive domains $[(93,94]$.
In clinical practice, it is not always easy to use these questionnaires most commonly due to lack of time. In addition, cultural and religion aspects may influence a poor response rate.

There is a need to develop new instruments that can be used in clinical practice and in different cultural contexts, to investigate sexual activity and related symptoms that can be directly related with urogynecological problems and as outcome measures for the impact of the treatments. FSFI and PISQ are very useful instruments for research (recommended); however, a shorter patient-friendly tool for clinical practice is not yet available (optional).

\section{Effect of treatment on HRQOL}

For patients undergoing prolapse or incontinence surgery, meaningful data on HRQOL can be reliably collected preand post-procedure. An increasing number of studies are evaluating the response of validated HRQOL instruments to therapeutic interventions for incontinence and pelvic floor dysfunction, however in comparison to studies focused on anatomic and physiological outcomes, relatively few have been published to date.

\section{Conclusions and recommendations}

Standardized QOL questionnaires are increasingly recognized as an important, and in many cases, necessary measure by which to judge the success of therapy. Some (e.g., PFDI) are especially useful for patients with concurrent prolapse or colorectal complaints. General questionnaires are more suitable for research than clinical practice, due to limited sensitivity in detecting clinically meaningful QOL changes.

General instruments are optional in clinical research studies and not recommended in practice. Incontinencespecific questionnaires, especially short-forms are recommended for clinical studies, and optional for clinical practice.

\section{Urethral mobility}

\section{Chahin Achtari}

\section{Introduction}

The definition of stress urinary incontinence (SUI) involves involuntary loss of urine caused by physical exertion such as coughing and/or sneezing leading to an elevation of the intra-abdominal pressure. The pathophysiology of this 
condition is a variable combination of urethral hypermobility and urethral sphincter deficiency. A certain degree of mobility is considered as normal and even necessary for the normal function of the urethra. In the resting position, the proximal urethra is maintained in a high retropubic position within the intra-abdominal pressure compartment like the rest of the bladder. The distal third of the urethra is fixed to the pubic bone through the perineal membrane, whereas the proximal urethra is mobile. The endopelvic fascia is a layer of connective tissue covering the ventral aspect of the levator ani muscle and is responsible for the support of pelvic organs. The periurethral endopelvic fascia connects the proximal part of the urethra to the arcus tendineus fascia pelvis and to the levator ani muscle. Urethral mobility depends on the muscular activity of the levator ani muscle, which is maintained within a certain limit by the fascial attachment. In the resting position, levator muscle tonic activity maintains the high retropubic position, and relaxation of the levator before micturition provokes a straightening of the posterior vesico-urethral angle and an opening of the urethra.

Urethral hypermobility is caused by a defect in the connective tissue that normally supports the urethra and anchors it to the surrounding structures or to muscular defect. It is widely accepted that urethral hypermobility is associated with SUI although this association is not systematic. In fact, there is no accepted definition of urethral hypermobility, as a certain degree of urethral sphincter incompetence is often associated leading to a wide overlap between normal and pathologic urethral mobility. Several tests are available to demonstrate the degree of urethral mobility, some of which allow direct visualization of the urethra and some that are indirect tests.

\section{Cotton-tipped swab test}

The cotton-tipped swab test (Q-tip) is an indirect clinical test evaluating the angle between a cotton swab introduced at the level of the bladder neck and the horizontal plane at rest and during a Valsalva maneuver. This test was initially described in 1971 [95] and subsequently standardized by Karram et al [96]. In the initial description, Crystle et al. found that patients with good urethral support had a rotation angle of less than $20^{\circ}$ so that an excursion of $30^{\circ}$ or more is generally regarded as bladder neck hypermobility. However, there is still a great variation in the way the test is performed, especially in the positioning of the patient and location of the cotton swab end.

The Q-tip test is inexpensive, simple, and easy to perform. It has therefore been widely utilized in studies to evaluate urethral mobility before and after SUI surgery or childbirth.
Karram and Bhatia [96] standardized performance of the Q-tip test. They demonstrated that the tip of the swab should be placed in the proximal urethra or urethra-vesical junction (UV), that the degree of bladder filling had no significant influence on the result, and that the result should be expressed in "maximal straining angle" instead of "positive/negative". In patients with anterior vaginal wall relaxation, there is no significant difference between the continent and incontinent groups, both being superior to $30^{\circ}$. In another study, Pollak et al. [97] found that the straining angle was altered, with a lesser maximal straining angle with the prolapse reduced. Also, it has been demonstrated that the position of the patient had an impact on proximal urethral mobility with an increased mobility in the supine over the standing position [98].

However, the Q-tip test is not a diagnostic test for SUI. In patients with SUI, the test is positive (i.e. $>30^{\circ}$ ) in $90 \%$, but it is also positive in about $30 \%$ of patients with bladder instability and in $50 \%$ with pelvic organ prolapse without stress incontinence. Although it was initially found to have a good correlation with bead chain cystourethrography, it has been criticized by Caputo and Benson who found poor correlation between UVJ mobility measured by ultrasound and a Q-tip test [99].

The Q-tip test should be performed in a standardized fashion, with the patient in lithotomy position, a welllubricated cotton-tipped swab is introduced into the urethra to the bladder. Gently withdraw until resistance is met, indicate the bladder neck position at the urethrovesical angle. Resting and straining angles are measured from the horizontal. A straining angle of $>30^{\circ}$ is a positive test for urethral hypermobility.

\section{Perineal sonography}

Ultrasound is a noninvasive, readily available, radiationfree and is easy test to perform. Perineal ultrasound is performed with a 3.5- to 5-MHz curved probe placed on the perineum, usually between the labia to enhance the visualization of pelvic organs. It allows direct visualization of the urethra, UVJ, and bladder. The fixed landmark that is usually used to measure the position and mobility of the UVJ is the symphysis pubis. Schaer et al. [100] described a method to measure bladder neck position in a twodimensional axis system, where the $X$ axis is a line passing through the central part of the symphysis pubis, and the $Y$ axis is perpendicular at the level of the lower border of the symphysis. Dietz [101] recommended use of a horizontal line at the inferoposterior margin of the symphysis as a landmark. With either method, it is easy to measure bladder neck position at rest and during Valsalva maneuver, bladder neck descent, and the posterior urethrovesical angle. It is 
also possible to have qualitative information about the bladder neck such as the presence of a funneling and sometimes visualization of urine passing in the proximal urethra.

Some parameters affect the measurement results, so the test should be performed in a standardized fashion [102]. Although bladder filling has little impact on bladder neck position, UVJ mobility is affected [103], so the test should be performed at a standardized bladder volume, such as $300 \mathrm{ml}$. Patient position and probe pressure on the perineum also affects bladder neck position, and it is recommended to perform the test in the supine position with low pressure on the perineum.

Unfortunately, there is no sonographic definition of UVJ hypermobility. Several studies looked at UVJ mobility in continent and stress incontinent patients [103, 104]. During Valsalva, the UVJ is displaced backwards and downwards in a rotational movement. Mobility can therefore be measured as a linear displacement, a descent, or a change in angle between two axes. Dietz and Wilson [103] showed that bladder neck descent of more than $25 \mathrm{~mm}$ and a retrovesical angle of $165^{\circ}$ were strongly associated with stress incontinence. Conversely, Peschers et al. [104] showed that the bladder neck can be mobile up to $32 \mathrm{~mm}$ in continent nulliparous patients. It would therefore be very useful to find a cutoff limit, above which we can speak about hypermobility even if it is not associated with stress incontinence. Until then, we can only be descriptive and report the measured mobility of the urethra. Perineosonography is optional in clinical trials and optional in clinical practice in patients with proven SUI to evaluate urethral mobility.

\section{Videocystourethrography}

Videocystourethrography (VCU) is a radiologic test allowing direct visualization of the bladder, urethra, and UVJ through a contrast medium instilled into the bladder. Urethral mobility can be appreciated on lateral views, although bony structures may impair the quality of images that can be improved by digital subtraction imaging. VCU has long been considered as the "gold standard" to investigate LUT dysfunction, as it can be combined with urodynamics.

The position of the bladder neck and the different angles can be measured to evaluate UVJ mobility. As with ultrasound, the posterior urethrovesical (PUV) angle can be measured between the two lines passing along the posterior urethra and the bladder base and should be $115^{\circ}$ or more. VCU allows visualization of the voiding phase, thus calculation of the urethropelvic angle. The distance between the internal urethral orifice and the symphysis
(SO) can also be measured and should not be less than $20 \mathrm{~mm}$. Correlation between VCU and perineal ultrasound has been found to be good for urethral mobility and PUV and SO [105]. VCU is optional for the evaluation of urethral mobility in clinical trials and not recommended in clinical practice, as it requires special facilities that are not available in all units, and it exposes patients to radiation.

\section{Conclusions and recommendations}

In conclusion, urethral mobility is an important aspect of the evaluation of SUI. An effort should be made by investigators and research committees to define urethral hypermobility and standardize the different techniques that should be performed before and after surgery for stress incontinence. Urethral hypermobility is diagnosed in virtually $100 \%$ of all cases of grades II-IV prolapse.

Urethral mobility assessment by Q-tip test (and/or optional perineal ultrasound) is recommended for both clinical research and practice in stages 0 and I. It is optional in stages $>\mathrm{I}$.

Q-tip test is optional for both clinical research and practice to assess urethral mobility. Perineal ultrasound is optional in research and clinical practice.

\section{Pelvic organ prolapse assessment}

\section{Chahin Achtari}

\section{Introduction}

The pelvic organ prolapse quantification (POPQ) system was introduced in 1995 to standardize the evaluation of pelvic organ prolapse. A document was published describing the POPQ, which was subsequently reviewed and adopted by the membership of the International Continence Society, American Urogynecologic Society, and the Society of Gynecologic Surgeons. The POPQ classification system is unique, in that it is the only system that has undergone extensive testing in several studies to validate its use as a tool to describe and study pelvic organ prolapse [106-110]. It requires measurement of the distance between six defined points within the vagina and the hymeneal ring. The position of each point will define the prolapse stage. The first defined point is point Aa which is situated $3 \mathrm{~cm}$ proximal to the external urethral meatus and roughly corresponds to the urethro-vesical junction (UVJ). Stages are assigned according to the most severe portion of the prolapse when the full extent of the protrusion has been demonstrated. However, a stage can be defined for each 
point: stage 0: no prolapse is demonstrated; stage I: the most distal portion of the prolapse is $>1 \mathrm{~cm}$ above the level of the hymen; stage II: the most distal portion of the prolapse is $<1 \mathrm{~cm}$ distal to the plane of the hymen; stage III: the most distal portion of the prolapse is $>1 \mathrm{~cm}$ below the plane of the hymen, stage IV: complete eversion of the total length of the lower genital tract. This system has an excellent inter- and intra-observer correlation and allows comparison within and between patients. It can therefore be expected that a precise measurement of the position of point Aa can be correlated with UVJ position and mobility.

Montella et al. [111] measured the descent of the urethro-vesical crease (point $\mathrm{Aa}$ ) and compared it to the Q-tip test to evaluate proximal urethral support in 111 patients complaining of prolapse and/or urinary incontinence; 83 patients $(75 \%)$ had a positive Q-tip test $\left(\geq 30^{\circ}\right)$. Descent of point Aa to $-2 \mathrm{~cm}$ from the hymen provided a good sensitivity of $94 \%$ but poor specificity (36\%). The optimal cutoff point was $-1 \mathrm{~cm}$ with a sensitivity of $67 \%$ and specificity of $61 \%$. There was a significant relationship between a positive Q-tip test and cutoff point ranging from -2 to $+1 \mathrm{~cm}(\mathrm{P}<0.05)$. At +2 or $+3 \mathrm{~cm}$, the positive predictive value was $100 \%$.

A similar study was performed by Cogan et al. [112] on 274 patients with urinary incontinence or pelvic organ prolapse. A correlation was calculated between points Aa and $\mathrm{Ba}$ and the Q-tip test. Although they found a moderately strong correlation between point Aa and Q-tip straining angle, with $r=0.47(P<0.001)$, one could not predict the other. However, at stages II, III, and IV for point Aa, urethral hypermobility is present in virtually $100 \%$ of patients.

Noblett et al. [113] confirmed that in stages II-IV, urethral hypermobility was found in $100 \%$ of cases. However, they found only $6 \%$ of patients at stage 0 for point Aa with hypermobility; at stage I, hypermobility was demonstrated in $91 \%$ with straining angles of $37.6 \pm 9.3^{\circ}$.

All studies agree that in stages II-IV for point Aa, the likelihood of finding urethral hypermobility is virtually $100 \%$. Therefore, the Q-tip test may not be necessary in these patients. In patients with stages $0-\mathrm{I}$, the positive predictive value is $82 \%$, and the negative predictive value is $94 \%$.

\section{Pop and stress incontinence}

As $10-40 \%$ of women with stress incontinence have a wellsupported urethra and inversely, $50 \%$ of continent women have urethral hypermobility as measured by the Q-tip test, Tapp et al. [114] studied the predictive value of point Aa and the Q-tip test to diagnose urodynamic stress incontinence. They compared 352 women with a diagnosis of urodynamic stress incontinence (USI) and 245 control cases. Point Aa was not associated with USI; in fact, an increasing Aa value was associated with reduced risk of USI, whereas the oddsratio of having stress incontinence with a positive Q-tip test was 3.10. The sensitivity of the cotton-tipped swab test for predicting stress incontinence was $80 \%$, with a specificity of $42 \%$, negative predictive value of $59 \%$, and positive predictive value of $67 \%$. The Aa point had a sensitivity of $37 \%$, specificity of $58 \%$, negative predictive value of $39 \%$, and positive predictive value of $56 \%$.

Among patients presenting with stress incontinence, Bai et al. [115] found $63.6 \%$ of coexisting prolapse (19/30). The majority $(53.3 \%)$ of these patients had stage II (16 of 30 ), and $50 \%$ had a point Aa substage for prolapse. Conversely, in patients presenting for greater than grade II pelvic organ prolapse, $62.6 \%$ had coexisting stress incontinence, with $52.2 \%$ having type II incontinence, yet half of the patients complaining only of mild incontinence.

When looking at clinical factors associated with severity of stress incontinence, Richter et al. found a negative correlation between increasing stage of prolapse measured by the POP-Q and severity of incontinence in patients with a POP-Q stages $0-$ II, showing twice as many episodes of incontinence compared to stages III/IV [116].

\section{Conclusions and recommendations}

In conclusion, POP-Q is useful for pelvic organ prolapse grading, but descent of point Aa is not a reliable method to quantify urethral mobility and has no correlation with stress incontinence. The only correlation is a negative one, so that a stage 0 or I for point Aa is associated with more severe incontinence. Prolapse assessment using POPQ is recommended for research and optional for clinical practice. Simplified $P O P Q$ or simple staging is recommended for clinical practice. $P O P Q-A a$ is not recommended for urethral hypermobility diagnosis.

\section{Patient satisfaction}

\section{Kimberly Kenton, Roger Goldberg}

Over the last several decades, patient expectations and satisfaction for surgical treatment have gained increasing attention, forcing surgeons to reevaluate traditionally used outcome measures. Patient satisfaction after medical treatment is primarily determined by patient expectations [117119]. Early research on patient expectations focused not on the patient's expectations, but on those of the primary care physician. However, differences between patient and physician perceptions of outcomes and satisfaction are becoming apparent throughout medicine [120]. Time- 
honored objective outcome measures used by physicians are no longer satisfactory for determining surgical success. Focus is increasingly shifting to the role of patient expectations and quality of life in determining the success of surgical treatments $[121,122]$.

Several validated general health and condition-specific quality of life measures (QOL) have been previously discussed. While these measures are essential components of outcome assessments, they are typically long and do not always relate the patient's overall clinical condition. For instance, a woman's overall score on the Pelvic Floor Distress Inventory (PFDI), a validated QOL instrument specific for incontinence, prolapse, and colorectal dysfunction, may not improve after successful pelvic reconstructive surgery due to the woman having significant distress from her bowel symptoms. As a result, these measures do not necessarily correlate with patient satisfaction after surgery, and research in reconstructive pelvic surgery has shifted to patient's goals for surgery and more global outcome measures.

Global indexes have been developed which ask patients to rate their overall symptom improvement after treatment $[123,124]$. Global indexes are typically short and provide the physician with an overall assessment of the patients' symptoms since treatment. The Patient Global Impression of Improvement (PGI-I) is a transition scale that has been validated after stress incontinence treatment in women [124]. (Table 4) The PGI-I was modeled after previously published psychopharmacologic scales by changing the stem to apply to LUT conditions [125]. The PGI-I is increasingly used to assess outcome after incontinence treatment $[126,127]$. It is the primary outcome measure in a large, national, randomized trial, the Refractory Urge Incontinence and Botox Injection trial, sponsored by the Pelvic Floor Disorders Network and the National Institute for Child Health and Human Development.

Research in reconstructive pelvic surgery reflects the trend towards patient expectations and goal selection in determining surgical outcomes. Hullfish et al. [128] reported long-term follow-up of patient-centered goals after

Table 4 Patient Global Impression of Improvement (PGI-I)

Check the one number that best describes how your urinary tract condition is now, compared with how it was before you began treatment

\begin{tabular}{ll}
\hline Rating & Description \\
1 & Very much better \\
2 & Much better \\
3 & A little better \\
4 & No change \\
5 & A little worse \\
6 & Much worse \\
7 & Very much worse \\
\hline
\end{tabular}

reconstructive pelvic surgery. Goal achievement remained high 1-3 years after surgery and was significantly associated with condition-specific quality of life measures. Women who experienced postoperative complications were less likely to achieve their goals. Patient satisfaction after reconstructive pelvic surgery correlated highly with achievement of self-described, preoperative surgical goals, while objective measures of surgical success correlated poorly with patient satisfaction [127]. Patient dissatisfaction was also highly associated with retrospectively feeling unprepared for surgery and routine postoperative events. One-year follow-up of this cohort demonstrated a high correlation between patient dissatisfaction regardless of goal achievement and developing overactive bladder symptoms [129].

In conclusion, a global assessment of patients' goals, expectations for treatment, and postoperative symptoms are recommended in both clinical practice and research to further aid our understanding of treatment outcomes.

\section{Urodynamic testing}

\section{Edward Stanford, Gunnar Lose}

\section{Role of UD testing}

The role of urodynamic testing (UD) includes discriminating between different types of stress urinary incontinence (SUI), diagnosing the severity of SUI, and identifying concomitant complicating factors such as outlet obstruction, detrusor hypoactivity, and detrusor overactivity. Ideally, comprehensive preoperative evaluation under standardized conditions should correctly identify patients with SUI. The goal therefore, of urodynamic testing is to provide objective confirmation of the signs and symptoms of lower urinary tract dysfunction (LUTD) [130]. While the diagnosis and optimal treatment of LUTD requires a careful history and objective evaluation, it has been demonstrated that urinary symptoms are not specific in predicting the dysfunction involved in the patient's incontinence [131-133]. According to expert consensus opinion, UD is the only way to understand why people are continent or incontinent because an attempt to gain that understanding is what constitutes urodynamics.

\section{Urodynamic testing}

Pad testing, questionnaires, evaluation of urethral hypermobility, and post-void residual (PVR) are referred to elsewhere in this article. 


\section{Uroflowmetry and post-void residual (optional)}

Uroflowmetry measures urinary flow time, flow rate, voided volume, and average flow rate. Post-void residual (PVR) measures the quantity of urine remaining in the bladder after voiding. The clinical utility of uroflowmetry measurements may be predictive of postoperative voiding dysfunction. Postoperative voiding function is predictably worse when preoperative voiding difficulties exist. Preoperative uroflowmetry showing voiding abnormalities such as Valsalva voiding or low flow rates may predict abnormal symptomatic voiding dysfunction postoperatively [134]. Furthermore, bladder emptying can be affected by age, medication use, fluid intake, and restriction, and voiding habits.

Uroflowmetry and PVR are simple, noninvasive voiding measures that should be performed on all patients with incontinence or voiding dysfunction. If abnormal, those tests should be repeated to document the reliability of the result.

\section{Cystometry (recommended)}

Cystometry (CMG) is the most accurate tool for the evaluation of bladder function with filling [135]. Simple office-based CMG may yield sufficient information to proceed with treatment and is therefore recommended. A positive cough stress test and single-channel CMG may be the minimally accepted tests before intervention [136].

Complex single-channel and multichannel CMG requires specialized, expensive equipment, and training to properly interpret the findings. Advantages are that fluid-filled CMG allows determination of pressure-related fluid loss, estimation of leak pressures, and simultaneous measures of multiple variables. The repeatability of measurements may be poor especially in non-neurogenic patients; therefore, repeated measures are suggested to establish bladder capacity and pressures [137]. This invasive test is recommended, especially if complicating factors are suspected.

\section{Pressure flow study (optional)}

Pressure flow (PF) measures the relationship between pressure in the bladder and urine flow rate during emptying and, hence, provides information about detrusor contractility and bladder outlet obstruction. It is recommended to investigate voiding dysfunction, specifically in those patients who had previous incontinence surgery and those with high residual urine volume.

\section{Urethral pressure profilometry (optional)}

Urethral pressure is defined as the fluid pressure needed to just open a closed (collapsed) urethra [138]. Conceptually, urinary leakage will not occur at any abdominal pressure under normal conditions. The main criticisms of urethral pressure measurements are that they do not discriminate urethral incompetence from other disorders, do not provide a measure of severity of the condition, and do not provide a reliable indicator to surgical success [134]. UD measurements of the urethra quantify urethral length and pressures relative to the bladder and abdominal pressures, as a means of quantifying the continence mechanism. Urethral pressure profilometry (UPP) are clinical tests that evaluate the functional status of the urethra in women, measuring intraluminal pressure along the length of the urethra. Studies include maximum urethral closure pressure (MUCP), functional urethral length (FUL), pressure transmission ratio (transmission index) (PTR), and leak point pressure (LPP). MUCP is an expression of the permanent acting closure forces, which includes the submucosa, the smooth muscle, the striated muscle, fibroelastic structures, and neural stimuli. MUCP is generally lower in incontinent women and decreases as a function of age [139]; however, there is a considerable overlap of measured values compared to continent women [140]. MUCP values in women with prior anti-incontinence surgery are typically lower [141].

The MUCP is a static UD measurement; therefore, it has been suggested that the UPP has limited clinical utility in the routine evaluation of the SUI patient [142, 143]. Defining the urethral closure mechanism, standardization of the methods of measurement of urethral pressure, the type, size, material used in the catheter, and orientation of the sensor within the urethra pose difficult questions in standardizing urethral pressure measurements. Weber concluded that due to the lack of standardization, urethral pressure profilometry is not a useful diagnostic tool for stress incontinence in women [144]. One conclusion is that its use in clinical management is not supported by current evidence, and many consider urethral pressure measurements to be a research tool.

Conversely, ignoring urethral pressure measurements may lead to a less successful surgical intervention in patients with SUI. Sand et al. [145] proposed a cutoff value of $<20 \mathrm{~cm}$ $\mathrm{H}_{2} \mathrm{O}$, as the subjective cure rate for a Burch retropubic colposuspension was lower (46\%) compared to patients with an MUCP of $>20 \mathrm{~cm} \mathrm{H}_{2} \mathrm{O}(82 \%)$ in women over age 50. In addition, various forms of voiding dysfunction related to abnormal urethral function deserve attention in the clinical setting [146]. The clinician needs to individualize the care of the patient with SUI and decide whether urethral pressure measurements play a role in their treatment. 


\section{Leak pressures (optional)}

McGuire et al. [147] first introduced the term, low pressure urethra when he described the detrusor leak point pressure (DLPP). The DLPP measures the resistance of the urethral sphincter relative to detrusor pressure and is useful in applying a pressure-based management approach to avoid renal deterioration in patients with myelodysplasia or spinal cord injuries.

The abdominal leak point pressure (ALPP) is defined as the intravesical pressure at which urine leakage occurs due to increased abdominal pressure in the absence of a detrusor contraction [116]. If the patient has a filling CMG that is negative, the ALPP is a useful provocative UD test that accurately recreates the circumstances associated with stress incontinence [148]. The ALPP therefore, has a role in understanding and defining urethral function during a Valsalva stress maneuver. The ICS does not define cutoff values qualifying low-pressure urethra, and the term ISD, or intrinsic sphincteric deficiency, is considered arbitrary. Typically, an ALPP of $<60 \mathrm{~cm} \mathrm{H}_{2} \mathrm{O}$ indicates intrinsic sphincteric dysfunction.

\section{Prolapse}

It is argued that $36-80 \%$ of women with advanced prolapse have potential incontinence and should undergo urodynamics before surgery [149]. Reduction of prolapse to uncover potential (occult or latent) incontinence masked by the prolapse is imperative [96, 150, 151]. Various techniques have been employed including vaginal pack, pessaries, rectal swabs, and Graves or Sims speculums [152-154].

\section{Outcomes and UD testing}

The ultimate goal of clinical urodynamics is to improve the basis of choosing the correct therapy and, hence improve outcome. In complex incontinence cases, multichannel UD testing is recommended to establish a baseline understanding of the pathophysiology. This is especially important before invasive treatment is carried out. A standardized approach to diagnosing patients with SUI is lacking; therefore, various parameters have been investigated in varied combinations to diagnose the patient's incontinence and voiding dysfunction, including ICI guidelines [130], AHCRP guidelines [155], positive stress tests $[156,157]$, urethral hypermobility [156158], maximum bladder capacity $>400 \mathrm{ml}$ [157], residual urine $<50 \mathrm{ml}$ [156-158], residual urine $<200 \mathrm{ml}$ [156], no previous surgery [156-158], age under 65 [156], and predominant stress incontinence by history [130, 156-159].
Comprehensive reviews conclude that the patient's history is inadequate in providing an accurate diagnosis, may lead to a misdiagnosis in up to $25 \%$ of cases, may not be predictive of the final diagnosis, and should not be used as the sole determinant of diagnosis or treatment [160-161].

It has been argued for over 30 years that without some form of objective urodynamic assessment, some patients will be subjected to unnecessary or ineffective surgery [162], and potential adverse outcomes, and surgical complications (hemorrhage, hematoma, bladder injury, urinary tract injury, urinary retention, failed surgery, and postoperative urinary dysfunction) may be avoided. Jarvis et al. [55] showed that clinical diagnosis was overdiagnostic of detrusor overactivity and under-diagnostic of SUI confirmed by UD testing. Moreover, when only symptom-based treatments are considered, outcome may be poorer in incontinent women [163]. Therefore, current standards suggest that patients with complicated pathophysiology should undergo some form of objective UD testing before treatment, particularly surgical treatment. Invasive-urodynamics is recommended in women if:

- Invasive or surgical treatment is considered

- Previous treatment for incontinence (surgical or nonsurgical) has failed

- Voiding dysfunction

- Neurologic disorder

- Unexplained incontinence.

However, patients with SUI as the dominant symptom will likely demonstrate genuine stress incontinence on UD testing. Thompson et al. [164] questioned the role of UD in SUI and found that in women $<50$ years, urodynamic evaluation was not predictive of outcome. A Cochrane Database review concluded that current data is lacking to determine if urodynamics affected clinical outcomes and that a larger definitive comparative trial is needed [165]. There is some evidence that MUCP or leak point pressure and detrusor overactivity predict persistent stress incontinence and postoperative urgency, respectively [166]. Patient satisfaction rates are lower in women who develop detrusor overactivity postoperatively [167, 168]. Patients with low urethral pressures may demonstrate detrusor overactivity after surgical correction and may go undetected until urethral pressure is restored [169]. Therefore, in some patients, UD testing plays an important role in predicting postoperative detrusor function.

\section{Conclusions and recommendations}

UD testing, despite certain limitations, continues to be the gold standard to define the pathophysiology of LUTD. It is 
argued that UD testing is not cost effective, limits access to specialty care, and requires specialized and expensive equipment, special training, and interpretation skills [169]. It is difficult and perhaps not appropriate to recommend universal testing in all patients when considering the uncomplicated forms of urinary incontinence. Symptoms, questionnaires, voiding diaries, physical examination, and pad testing are not predictive of the final diagnosis and may lead to misdiagnosis; thus, UD testing is considered by many to be an essential component of the work-up of the incontinent patient.

Noninvasive urodynamics (post-void residual volume determination and possibly uroflowmetry) is recommended in all incontinent patients for both practice and clinical research. Multichannel urodynamic studies are recommended if planned treatment is irreversible, especially in those with mixed incontinence and those who have symptoms or signs of voiding difficulty as well. However, in those patients whose predominant symptom is stress incontinence, UD testing may not be necessary.

Invasive urodynamics is recommended in women if invasive or surgical treatment is considered, surgical and conservative treatment fails, or in cases of voiding dysfunction, neurologic disorder, or unexplained incontinence.

\section{Neurophysiological testing of the pelvic floor for the diagnosis of stress urinary incontinence}

\section{Kimberly Kenton}

Electrodiagnostic (EDX) testing of the pelvic floor is becoming increasingly common in clinical pelvic medicine and pelvic floor research. Clinically, it can be used with history, physical examination, and urodynamic testing to aid in the diagnosis of certain pelvic floor disorders and to determine if a central or peripheral neurologic problem exists. Electrodiagnostic testing is also emerging in studies investigating the etiology of pelvic floor disorders. A basic understanding of the principles and techniques used in EDX medicine are essential for reconstructive pelvic surgeons. The aim of this discussion is to introduce reconstructive pelvic surgeons (urogynecologists, urologists, and colorectal surgeons) to the principles of neurophysiologic testing and to the relevance of neurophysiologic testing in the pelvic floor and urinary incontinence.

\section{Pudendal and perineal nerve conduction studies}

\section{Clinical applications}

Pudendal nerve conduction studies (NCS) are the most commonly reported EDX tests done on the pelvic floor.
Pudendal and perineal NCS established the link between pudendal neuropathy and stress urinary incontinence and fecal incontinence [170-174]. Prolonged terminal motor latencies have also been shown after vaginal incontinence and prolapse surgery, $[175,176]$ suggesting that some anterior vaginal wall dissection leads to distal pudendal nerve injury. Pudendal nerve terminal motor latencies (PNTML) are most frequently reported in case series of women undergoing anal sphincteroplasty. Authors reported varying degrees of postoperative success in patients with prolonged PNTML [177179]. The clinical usefulness of pudendal and perineal nerve terminal motor latencies is hotly debated. They should not be used in isolation from other EDX tests when evaluating pelvic floor injuries. Generally, EMG follows NCS, as EMG is more sensitive for detecting neuropathic injury.

\section{Sacral reflex testing}

Clinical applications

Urethral-anal and bladder-anal reflexes involve visceral afferent fibers from the urethra or bladder, which synapse in the conus medullaris and travel through pudendal efferents to the external anal sphincter. Injuries to the pelvic plexus or cauda equina frequently result in absence of the urethral and bladder-anal reflexes. The clitoral-anal reflex passes through the pudendal afferents to the spinal cord and back through pudendal efferent fibers to the anal sphincter. These roots are often affected in cauda equina disease and are not affected in conditions that disrupt the pelvic plexus.

Anything that affects the pelvic plexus can potentially disrupt the urethral and bladder-anal reflexes, such as peripheral neuropathies with significant autonomic components and radical pelvic surgery or radiation. The clitoralanal reflex should be preserved because the course of this branch is not involved. Pudendal neuropathy typically results in prolonged or absent clitoral-anal reflex with preservation of the urethral and bladder-anal reflexes. The afferent limb of the pathway through the pelvic plexus is less affected and is a temporally longer portion of the pathway. Lesions in the conus medullaris and cauda equina frequently produce abnormalities in all sacral reflexes. Suppression of the urethral-anal reflex by actively trying to void is a measure of upper motor neuron function [180]. If a patient is unable to suppress the response during voiding, she may have a lesion in the suprasacral spinal cord.

\section{Electromyography}

EMG is the gold standard for studying peripheral striated neuromuscular disease. It involves the recording and study 
of electrical activity from striated muscles and can be used to distinguish between normal, denervated, denervated and reinnervated, and myopathic muscle. The electrical activity can be recorded using surface or needle electrodes. Voluntary electrical activity is recorded as motor unit action potentials (MUAP), which represent the summation of activity from multiple motor units. Motor units are comprised of a single anterior horn cell, its axon, and all the skeletal muscle fibers it serves.

The most common electrodes used in the pelvic floor are surface and concentric needle (CNE). Surface electrodes are placed on the skin over the muscle being evaluated to evaluate patterns of muscle activity and are commonly used during urodynamic studies to assess urethral sphincter activity. However, neuromuscular activity from multiple pelvic floor muscles is recorded, not just the striated urethral sphincter, making it difficult to differentiate which muscle is contributing to the signal. A recent study comparing perineal surface to urethral $\mathrm{CNE}$ during urodynamics demonstrated that $\mathrm{CNE}$ tracings were consistently more interpretable than surface recordings [181]. Needle tracings demonstrated urethral relaxation with voiding $79 \%$ of the time, while surface recordings only demonstrated urethral relations $28 \%$ of the time.

Three types of activity can be recorded with $\mathrm{CNE}-$ insertional, spontaneous, and MUAPs. Insertional activity is the electrical activity detected by the CNE as it passes through the muscle at rest. Decreased insertional activity indicates that the electrode is not in muscle or the muscle has undergone severe atrophy and replacement by electrically inactive tissue. This is commonly seen in the anal sphincter at the 12 o'clock position in women with longstanding anal sphincter disruptions.

Spontaneous activity is persistent electrical activity after the CNE is inserted and results from marked membrane instability of the muscle or neuron innervating it. Fibrillation potentials and complex repetitive discharges (CRDs) are common types of insertional activity. Complex repetitive discharges are associated with neuropathy and voiding dysfunction in women. Fowler's syndrome, first described in 1985, is the triad of urinary retention, urethral CRDs, and polycystic ovaries in young women [182]. Retention in this group of patients is thought to be due to "overactivity" of the striated urethral sphincter, due to direct spread of electrical excitation from muscle fiber to muscle fiber.

Motor unit action potential analysis in the sphincters can be done at rest and with voluntary activity. Nerve injury results in characteristic changes in MUAP parameters of duration, amplitude, and polyphasia. After nerve injury, a muscle fiber can be reinnervated by regrowth of the original axon or a nearby axon. If a nearby axon reaches the denervated muscle fiber, it will supply more muscle fibers creating a more complex MUAP. The new complex waveform tends to be polyphasic (number of times a MUAP crosses the baseline). New axons are initially not well myelinated and conduct impulses more slowly; as a result, newly reinnervated muscle has long duration MUAPs. The MUAPs have larger amplitudes, as one motor unit is supplying more muscle fibers.

\section{Clinical applications}

Concentric needle EMG has been used in pelvic floor muscles to confirm the association between pelvic nerve injury and vaginal delivery, stress incontinence, and fecal incontinence. Significant changes in MUAP morphology have been reported after vaginal childbirth by multiple authors [183-185]. Needle EMG of the levator ani and external anal sphincter muscles has shown EMG evidence of denervation with reinnervation in women with stress urinary incontinence and pelvic organ prolapse [185, 186]. Two studies have used quantitative CNE of the urethral sphincter in women undergoing continence surgery [187, 188]. Fisher et al. [187] demonstrated more advanced neuropathic changes in women with persistent stress urinary incontinence. Kenton et al. [188] studied 89 women undergoing Burch urethropexy with $\mathrm{CNE}$ and found significant differences in EMG parameters of women with successful incontinence surgery, suggesting that these women had better innervation of their urethral sphincters.

Gregory recently reported quantitative CNE data from the anal sphincter of 23 nulliparous and 28 vaginally parous women. Motor unit action potentials from the 23 nulliparas had significantly higher amplitudes, longer durations, and more phases, lending further evidence that vaginal childbirth results in pudendal neuropathy [184]. Some normative CNE MUAP parameters have been reported for the external anal sphincter and levator ani $[185,189]$. No normative data exists for the striated urethral sphincter.

\section{Conclusions and recommendations}

Electrodiagnostic testing has both clinical and research applications in pelvic floor disorders. Clinical evidence suggests that certain types of reconstructive surgery may impact pelvic floor innervation. Zivkovic measured perineal nerve terminal motor latencies before and after vaginal reconstructive surgery and found significantly prolonged terminal motor latencies in women who underwent vaginal needle suspension procedures [176]. Similarly, Benson found significantly prolonged pudendal and perineal nerve terminal motor latencies in women undergoing vaginal prolapse repair, while the terminal motor latencies of women undergoing abdominal repair were not different [190]. Pudendal neuropathy was significantly more com- 
mon in the women with "suboptimal" repairs [191]. In a randomized trial of abdominal vs vaginal reconstructive surgery, Benson found superior anatomic results of prolapse repair in the abdominal group [175]. Another randomized trial also demonstrated anatomic superiority of the abdominal approach [192]. These data suggest that vaginal reconstructive surgery may result in denervation of the pelvic floor musculature, which impacts anatomic success of the surgery. There is also increasing data that preoperative pelvic floor denervation may impact surgical outcomes, particularly for continence procedures. Two recent studies demonstrated a relationship between urethral sphincter neuropathy and outcome of continence surgery [187, 188].

Pelvic floor EDX studies may aid in the clinical diagnosis of some pelvic floor disorders and help to predict outcomes of incontinence surgery. However, confirmatory studies are necessary. In a neurologically normal patient, electrodiagnostic testing is not recommended for clinical research or practice to evaluate female stress urinary incontinence.

\section{Surgical complications in the treatment of stress urinary incontinence}

\section{Edward Stanford, Eckhard Petri}

\section{Introduction}

The operative approach to correct stress urinary incontinence (SUI) may include abdominal, vaginal, laparoscopic, and combined procedures. In addition, different materials used in the procedure may include autologous tissue (rectus fascia and tensor fascia lata), xenografts (porcine dermis, porcine intestinal submucosa, bovine pericardium, and others), synthetic grafts, and combined synthetic and biologic grafts.

Pelvic surgeons should be skilled in the prevention, early detection and correction of surgical complications [193].

\section{Incidence}

It appears that the risk of LUT injury is similar for vaginal, abdominal, and laparoscopic surgical approaches, although the risk of LUT injury during laparoscopy appears to increase with the increasing complexity of the procedure. Complications listed below related to SUI surgical procedures can potentially involve any of the organs of the pelvis.

- Bladder injuries

- Urethral injuries

- Ureteral injuries
- Intestinal injuries

- Erosions

- Hemorrhage

- Fistulae

- Prolapse

- Voiding dysfunction

- Postoperative OAB

- ISD

- Recurrent incontinence

- Dyspareunia

- Pain

Lower urinary tract injury

The actual incidence of injury during Burch colposuspension is unknown. Ureteric injury, retroperitoneal urinoma, and ureteral ligation are reported [194-197]. Urethra injury is relatively uncommon with the Burch procedure. Bladder injury is more common with laparoscopic Burch, with one study reporting a $2.3 \%$ incidence of cystotomy (4 of 171 ; [198]).

Intravesical sutures have been reported in almost all SUI surgical procedures [199]. These patients often present with bladder or pelvic pain, frequency, urinary tract infection, or recurrent incontinence. Stevenson et al. [200] reported a 9\% incidence of intraoperative bladder or ureteral injury during the Burch procedure, many of which are recognized after surgery, arguing that cystourethroscopy is recommended to visualize the bladder and urethra during surgery to avoid this surgical complication.

Unfortunately, we can only rely on isolated reports occasionally published in the surgical literature to get an idea of the incidence and severity of complications. Miscellaneous complications reported after the Burch procedure, include massive hemorrhage requiring transfusion, hematoma, bladder injuries diagnosed intraoperatively and postoperatively, ureteral kinking, urinary retention, wound infection, pelvic abscess, UTI, and DVT [201]. Similarly, a university teaching program reported complications from 151 open Burch procedures over a 5-year period, which included LUT injury $<1 \%$, cystotomy $1.3 \%(N=2)$, intravesical suture $0.7 \%$ $(N=1)$, transfusion $0.7 \%(N=1)$, postoperative ileus $1.3 \%$ $(N=2)$, incisional complications $3 \%$, of which five had cellulites, and one suffered an incisional separation, urinary retention $0.7 \%(N=1)$, and de novo detrusor overactivity $8 \%$ [202]. Paraiso et al. [203] reported an $8 \%$ risk of unrecognized injury with Burch which included two intravesical sutures, one bowel injury, one hematoma, one pelvic abscess, one postop ileus, one pulmonary embolus, one pyelonephritis, two with recurrent incontinence requiring collagen periurethral injections, and a $34.5 \%$ incidence of detrusor overactivity treated with anticholinergics. 
Voiding dysfunction

Voiding dysfunction such as frequency, nocturia, urgency with and without incontinence, hesitancy, retention, incomplete emptying, and recurrent urinary tract infections have been reported after all anti-incontinence procedures. Voiding dysfunction after retropubic colposuspension and mid-urethral sling procedures is usually transient and resolves postoperatively [204, 205]. The incidence of de novo detrusor overactivity and urge urinary incontinence varies depending upon the anti-incontinence procedure with rates as high as $33 \%$. Comparing retropubic vs TO slings, the incidence of urge urinary incontinence and detrusor overactivity rates are lower after TO slings [206]. Patients with detrusor pressures less than $15 \mathrm{~cm} \mathrm{H}_{2} \mathrm{O}$ are at risk for postoperative urinary retention [204]. After tension-free vaginal tape (TVT), voiding dysfunction can be as high as $26 \%$, requiring $>24 \mathrm{~h}$ of catheterization in $11 \%$ and tape division in $1.3 \%$ (207).

\section{Extrusion and erosion}

It is argued that the actual incidence of complications is not known due to underreporting, and studies comparing success rates, complications, and erosion rates are lacking [208]. It is clear, however, that after all anti-incontinence surgeries, erosion and migration of suture material, bolsters, supporting tacks, and synthetic mesh material can occur. Bone anchor material is used less often due to reports of osteitis pubis and osteomyelitis at times requiring osteotomy and removal.

The type of mesh material used in mid-urethral slings and prolapse surgery is of importance as some materials demonstrate higher erosion and extrusion rates than others. Higher rates are reported with synthetic mesh that is woven with small pore size, as macrophage migration to deposit collagen and engulf bacteria is hindered (e.g., ObTape and GoreTex). Fortunately, these materials have been replaced with loosely knitted, macroporous ( $>75 \mathrm{uM})$, monofilament polypropylene material with lower complication rates [209].

Mesh extrusion is usually treated with local excision in the office setting. However, erosion of materials used can become a major complication. At times, extensive surgery may be necessary and may involve retropubic, vaginal, intravesical, and abdominal approaches, at times, resulting in considerable morbidity. Deng et al. [210] report on 26 urethral and bladder erosions treated with a combination of urethrolysis with mesh removal, urethral reconstruction with graft, and bladder excision.

Failure

Recurrent SUI, both short-term (1-year) and long-term (5-years) varies depending upon the anti-incontinence procedure. Bhatia and Bergman [211] reported on the objective success rates for a modified Burch $(98 \%)$ vs a Pereyra needle suspension $(82 \%)$ at 1 -year performed for SUI. A 5-year follow-up reported objective continence rates after three procedures: anterior colporrhaphy (37\%), Pereyra procedure (43\%), and the modified Burch retropubic colposuspension (82\%) [212]. It appears that mid-urethral slings, both TVT and TO approaches, will demonstrate lower SUI recurrence; however, long-term follow-up studies are forthcoming.

\section{Complications of sling urethropexy procedures}

Sling urethropexy procedure can be performed via different approaches which influences the type of complications encountered. (Table 5) Complications reported for the sling urethropexy include erosion of sling material, bladder and urethral laceration, urethral amputation, and urethrovaginal and vesicovaginal fistulae.

In the previously mentioned report by Paraiso et al., the TVT procedure was compared to the Burch. Complications in the TVT arm included two cystotomies, one blood transfusion, one hematoma, one pelvic abscess, two with retention requiring mesh transection, one vaginal erosion, and $23.5 \%$ requiring anticholinergics for urge urinary incontinence. The 1-year success rate as per urodynamic testing was $96.8 \%$. Comparatively, urge urinary incontinence or detrusor overactivity are probably less after transobturator (TO) approaches [215].

\section{Prevention}

There is no substitute for good surgical training, a thorough preoperative history and diagnostic work-up to recognize risk factors, and a permanent awareness of the close proximity of the urinary tract, bowel and major neurovascular bundles in the pelvis. Most intraoperative LUT

Table 5 Potential complications: sling urethropexy

\begin{tabular}{|c|c|}
\hline $\begin{array}{l}\text { Ascending retropubic } \\
\text { approach }\end{array}$ & $\begin{array}{l}\text { Risks: bladder, intestinal and vascular } \\
\text { injury }\end{array}$ \\
\hline $\begin{array}{l}\text { Descending retropubic } \\
\text { approach }\end{array}$ & $\begin{array}{l}\text { Risks: bladder perforation, vascular } \\
\text { injury }\end{array}$ \\
\hline Mixed retropubic approach & $\begin{array}{l}\text { Risks: same for ascending and } \\
\text { descending approaches }\end{array}$ \\
\hline Transobturator approach & $\begin{array}{l}\text { Risks: bladder perforation, urethral } \\
\text { injury, vaginal perforation }\end{array}$ \\
\hline Fascial slings & Risks: pain, hematoma, infection \\
\hline Bone anchor slings (213) & Risks: pain, osteitis \\
\hline $\begin{array}{l}\text { Silicone-coated polyester } \\
\text { suburethral sling }\end{array}$ & $\begin{array}{l}\text { Risks: vaginal extrusion of the sling } \\
\text { material (214) }\end{array}$ \\
\hline
\end{tabular}


injuries occur during otherwise uncomplicated procedures, and injuries occur even in the "best of hands". Routine preoperative evaluation with renal and pelvic sonogram, intravenous pyelogram, and cystourethroscopy are not universally available and may be cost prohibitive. However, a prudent and directed work-up may warrant their use. Most important is the proper selection of patients for the chosen procedure with care and attention to detail in the performance of the procedure following standardized techniques. Nilsson et al. [216] showed in Finland that TVT sling complications exceeded $30 \%$ with less than 20 procedures that were performed per year, not being reduced beyond a level of $15-18 \%$ with more than $40-80$ procedures performed.

Dwyer et al. [199] demonstrated that intraoperative cystoscopy may not detect the presence of intravesical sutures. In a study by Kuno et al. [217], the use of prophylactic ureteral catheters did not affect the rate of ureteral injuries. A low incidence of urinary injuries can only be attributed to meticulous surgical techniques. This seems to be of increasing importance for those institutions in favor of laparoscopic hysterectomies and incontinence or prolapse surgery.

\section{Diagnosis and treatment}

Immediate recognition and correction is the best option for resolution of surgical complications. Naturally, the appropriate treatment is dependent upon the type of complication encountered. Unfortunately, diagnosis is made after the operation in more than two-thirds of the patients. Any atypical postoperative symptoms, such as prolonged moderate temperature and/or diffuse pain should always prompt a work-up. Renal sonography, intravenous pyelography, cystometrogram, computed tomography (CT) or MRI scanning, cystourethroscopy, ureteral stenting, or an intravaginal examination to rule out injury, perforation, laceration, hydronephrosis, ureteral ligation, hematoma, bleeding, or fistula may be required.

Symptoms and signs are variable, depending upon the location and the etiology. Direct lacerations lead to early leakage of urine; devascularization may delay diagnosis from 10-12 days up to several months. In a group of 72 women with 77 ureteral lesions, the interval to diagnosis was more than 10 days in $50 \%$ of the patients [218].

\section{Conclusions and recommendations}

As described above, the best treatment is prevention and early recognition of surgically related injury or postoperative complications. This implies either adequate skills of the surgeon himself to perform reconstruction or easy access to trained surgeons who can assist. It must be recommended to carefully select procedures depending upon the surgeon's skills and the capabilities of the institution. All complications (early and delayed) should be reported in research and clinical practice.

\section{Cost effectiveness in incontinence research}

\section{Safwat Tosson}

\section{Introduction}

It is expected that the aging population will increase, and therefore, the number of cases of incontinence will increase. Most health care markets have limited resources [219], and clinicians will have to compete for these resources to treat their patients. Therefore, cost effectiveness research is important to be able to provide continence services, and help both physicians and their patients make informed choices.

\section{Measuring costs}

Accounting and billing systems may be able to measure "gross costing" and "micro-costing" [220]; however; they are not available in all health care systems, and they do not measure the entire cost of the condition. Different accounting systems may give different cost estimates, and they do not measure the social costs and burden.

\section{Categorizing costs}

Costs may be categorized into the following:

- Measurement of direct cost "value" of all goods and services and other resources used to treat the condition and the consequences of incontinence [221]. This includes diagnosis, treatment, incontinence pads, and consequences of the condition.

- Indirect costs, including the value of lost productivity or morbidity.

- Intangible costs, including pain and suffering.

\section{Economic analysis}

There are many methods of economic analysis of health care, including:

1. Incontinence-specific outcomes, including urodynamics, pad test, urinary diaries, etc. 
2. Health starters and quality of life measurements, such as the SF-36 Nottingham Health Profile, The World Health Organization Quality of Life, and others.

3. The "value" of pelvic floor health may also be measured economically and include measurement of a willingness to pay (WTP), which showed that the willingness to pay was significantly related to the degree of reduction in incontinence episodes [222]. The Disability Adjusted Life Year (DALY) is based on the years of life lived with disability and the years of life lost due to premature death; it was formulated to determine a correlation between disease burden and cost of health care to treat it [223, 224]. The Quality Adjusted Life Year (QALY) [225-228] is the relationship between the value of a given health state and the length of time a person lives in this health status. The person measures the value of intervention in relation to live-death state. This measure also enables health economists to compare between various disease conditions and interventions.

4. Very few studies included QALY's parallel to randomized studies to evaluate surgical or medical intervention [229-230]

\section{Recommendations}

Most studies include direct cost analysis because they measure costs from the perspective of the health provider and not the patient, and exclude both the patient's and physician's born costs. Cost analysis should be made in current year dollars. It is recommended that quality cost effectiveness research is included in randomized studies. It would be beneficial for decision makers if QALY is used more often in future research.

\section{Summary of recommendations}

The IUGA guidelines were written by a consensus of IUGA members and experts in the field as recommendations for practice and are not meant to substitute for good clinical judgment nor replace the unique physician-patient relationship. They were developed to facilitate communication between physicians working in the field, and help to standardize research measures and allow comparison between different studies. They are meant to be categorical to allow for individual and global variations. As there is disagreement in the literature throughout these guidelines, the corresponding rating schemes and strength of the evidence were not included. The IUGA guidelines for SUI evaluation for both clinical practice and research are not legally binding and are subject to future revision.
Suggestions for reviewers

For research papers reporting on surgical treatment outcome and submitted for publication, at least 1 year followup is recommended. Shorter periods of follow-up should be used only to report on technical feasibility, safety, intraoperative and immediate postoperative complications.

Abstracts may contain early outcome of at least 6 months.

Definition of SUI treatment outcome

Should include all aspects of the disease, usually a combination of subjective and objective measures, and patient's degree of satisfaction/quality of life.

Summary of IUGA recommendations for SUI outcome measures

\begin{tabular}{|c|c|c|}
\hline Parameter & $\begin{array}{l}\text { Clinical } \\
\text { practice }\end{array}$ & Research \\
\hline Clinical evaluation & $\mathrm{R}$ & $\mathrm{R}$ \\
\hline Voiding diary & $\mathrm{O}$ & $\mathrm{R}$ \\
\hline Cough stress test & $\mathrm{R}$ & $\mathrm{R}$ \\
\hline Empty supine stress test & $\mathrm{O}$ & $\mathrm{O}$ \\
\hline Incontinence severity & $\mathrm{O}$ & $\mathrm{R}$ \\
\hline Visual analog score & $\mathrm{N}$ & $\mathrm{N}$ \\
\hline Stamey's grading & $\mathrm{O}$ & $\mathrm{O}$ \\
\hline $\begin{array}{l}\text { Severity measures (e.g., Sandvik index, } \\
\text { UDI-6) }\end{array}$ & $\mathrm{O}$ & $\mathrm{R}$ \\
\hline Pad test ( 1 and $24 \mathrm{~h})$ & $\mathrm{O}$ & $\mathrm{R}$ \\
\hline Quality of life measures & $\mathrm{O}$ & $\mathrm{R}$ \\
\hline General health questionnaires & $\mathrm{N}$ & $\mathrm{O}$ \\
\hline Incontinence-specific questionnaires & $\mathrm{O}$ & $\mathrm{R}$ \\
\hline Sexual dysfunction & $\mathrm{O}$ & $\mathrm{R}$ \\
\hline Urethral/ bladder neck mobility & $\mathrm{R}$ & $\mathrm{R}$ \\
\hline Q-tip & $\mathrm{O}$ & $\mathrm{O}$ \\
\hline Perineal ultrasound & $\mathrm{O}$ & $\mathrm{O}$ \\
\hline Prolapse anatomy & $\mathrm{R}$ & $\mathrm{R}$ \\
\hline POP-Q & $\mathrm{R}$ & $\mathrm{R}$ \\
\hline $\begin{array}{l}\text { POP-Q staging or Baden-Walker half- } \\
\text { way grading }\end{array}$ & $\mathrm{R}$ & $\mathrm{R}$ \\
\hline Patient's satisfaction and assessment & $\mathrm{R}$ & $\mathrm{R}$ \\
\hline Expectations & $\mathrm{O}$ & $\mathrm{R}$ \\
\hline Goals & $\mathrm{O}$ & $\mathrm{R}$ \\
\hline Postoperative symptoms & $\mathrm{R}$ & $\mathrm{R}$ \\
\hline Urodynamic testing & $\mathrm{R}$ & $\mathrm{R}$ \\
\hline Post-void residual urine volume & $\mathrm{R}$ & $\mathrm{R}$ \\
\hline Uroflow & $\mathrm{O}$ & $\mathrm{R}$ \\
\hline Cystometry & $\mathrm{R}$ & $\mathrm{R}$ \\
\hline Pressure flow & $\mathrm{O}$ & $\mathrm{O}$ \\
\hline Urethral pressure profile & $\mathrm{O}$ & $\mathrm{O}$ \\
\hline $\begin{array}{l}\text { Leak pressure (abdominal and/or } \\
\text { detrusor) }\end{array}$ & $\mathrm{O}$ & $\mathrm{O}$ \\
\hline Electrodiagnostic testing & $\mathrm{N}$ & $\mathrm{N}$ \\
\hline Reporting complications & $\mathrm{R}$ & $\mathrm{R}$ \\
\hline Cost analysis & $\mathrm{N}$ & $\mathrm{O}$ \\
\hline
\end{tabular}

$R$ Recommended, $O$ optional, $N$ not recommended 
Acknowledgment Many thanks and sincere gratitude to Kristin Dunn for hours of arduous edits and coordination.

\section{References}

1. Roongruangsilp U, Lertsithichai P, Kochakarn W, Ratana-Olarn $\mathrm{K}$ (2005) Correlation between symptoms and urodynamic findings in female patients with urinary incontinence. J Med Assoc Thai 88(3):364-370

2. Bo K, Sherburn M (2005) Evaluation of female pelvic-floor muscle function and strength. Phys Ther 85(3):269-282

3. Pels RJ, Bor DH, Woolhandler S et al (1989) Dipstick urinalysis screening of asymptomatic adults for urinary tract disorders. II. Bacteriuria JAMA 262:1221

4. Coombs GM, Millard RJ (1994) The accuracy of portable ultrasound scanning in the measurement of residual urine volume. J Urol 152:2083-2085

5. Cundiff GW, Bent AE (1996) The contribution of urethrocystoscopy to evaluation of lower urinary tract dysfunction in women. Int Urogynecol J 7:307-311

6. Ludviksson K (1997) The value of clinical examination of the female incontinent patient. Acta Obstet Gynecol Scand 76 (Suppl):19-23

7. Abrams P, Feneley R, Torrens M (1983) Patient assessment. In: Abrams P, Feneley R, Torrens M (eds) Urodynamics, 1st edn. Springer, New York, pp 6-27

8. Abrams P, Cardozo L, Magnus F et al (2002) The standardization of terminology of lower urinary tract function: report from the standardization sub-committee of the International Continence Society. Neurourol Urodynam 21:167-178

9. Rabin JM, McNett J, Badlani GH (1993) Computerized voiding diary. Neurourol Urodyn 12:541-554

10. Planes Hansen C, Klarskov P (1998) The accuracy of the frequency-volume chart: comparison of self-reported and measured volumes. Br J Urol 81:709-711

11. McCormack M, Infante-Rivard C, Schick E (1992) Agreement between clinical methods of measurement of urinary frequency and functional bladder capacity. Br J Urol 69:17-21

12. Abrams P, Klevmark B (1996) Frequency volume charts: an indispensable part of lower urinary tract assessment. Scand J Urol Nephrol Suppl 179:47-53

13. Baily R, Shepherd A, Tribe B (1990) How much information can be obtained from frequency/volume charts. Neurourol Urodyn 9:382-385

14. Groutz A, Blaivas JG, Chaikin DC et al (2002) Voiding and incontinence frequencies: variability of voiding diary data and required daily length. Neurourol Urodyn 21:205-209

15. Nygaard I, Holcomb R (2000) Reproducibility of the seven-day in women with stress urinary incontinence. Int Urogynecol $\mathrm{J}$ $11: 15-17$

16. Larsson G, Abrams P, Victor A (1991) The frequency/volume chart in detrusor instability. Neurourol Urodyn 10:533-543

17. Larsson G, Victor A (1992) The frequency/volume chart in genuine stress incontinent women. Neurourol Urodyn 11:23-31

18. Fink D, Perucchini D, Schaer G et al (1999) The role of the frequency-volume chart in the differential diagnostic of female urinary incontinence. Acta Obstet Gynecol 78:254-257

19. Brown JS, McNaughton KS, Wyman FJ et al (2003) Measurement characteristics of a voiding diary for use by men and women with overactive bladder. Urology 61(4):802-809

20. Norton P, Karram W, Wall LL et al (1994) Randomized doubleblind trial of terodiline in the treatment of urge incontinence in women. Obstet Gynecol 84(3):386-391
21. Zinner NR, Mattiasson A, Stanton SL (2002) Efficacy, Safety, and tolerability of extended- release once daily tolterodine treatment for overactive bladder in older versus younger patients. J Am Geriatr Soc 50(5):799-807

22. Boedker A, Lendorf A, H-Nielsen A et al (1989) Micturition pattern assessed by the frequency/volume chart in a healthy population of men and women. Neurourol Urodynam 8:421-422

23. Kassis A, Schick E (1993) Frequency-volume chart pattern in a healthy female population. Br J Urol 72:708-710

24. Larsson G, Victor A (1988) Micturition patterns in a healthy female population, studied with a frequency/volume chart. Scand J Urol Nephrol Suppl 114:53-57

25. Saito M, Kondo A, Kato T, Yamada Y (1993) Frequency-volume charts: comparison of frequency between elderly and adults patients. Br J Urol 72:318-341

26. Fitzgerald MP, Stablein U, Brubaker L (2002) Urinary Habits among asymptomatic women. Am J Obstet Gynecol 187 (5):1384-1388

27. Swift SE, Yoon EA (1999) Test-retest reliability of the cough stress test in the evaluation of urinary incontinence. Obstet Gynecol 94:99-102

28. Swift SE, Ostergard DR (1995) Evaluation of current urodynamic test methods in the diagnosis of genuine stress incontinence. Obstet Gynecol 86:85-91

29. Scotti RJ, Myers DL (1993) A comparison of the cough stress test and single-channel cystometry with multichannel urodynamic evaluation in genuine stress incontinence. Obstet Gynecol 81:430 433

30. Wall LL, Wiskind AK, Taylor PA (1994) Simple bladder filling with a cough stress test compared with subtracted cystometry for the diagnosis of urinary incontinence. Am J Obstet Gynecol 171:1472-1479

31. Mclennan MT, Bent AE (1998) Supine empty stress test as a predictor of low Valsalva leak point pressure. Neurourol Urodyn 17:121-127

32. Hsu THS, Rackley RR, Appell RA (1999) The supine stress test: a simple method to detect intrinsic urethral sphincter dysfunction. J Urology 162:460-463

33. Lobel RW, Sand PK (1996) The empty supine stress test as a predictor of intrinsic urethral sphincter dysfunction. Obstet Gynecol 88:128-132

34. Walter AJ, Thornton JA, Steele AC (2004) Further characterization of the supine empty stress test for predicting low Valsalva leak point pressure. Int Urogynecol J 15:229-301

35. Weidner AC, Myers ER, Visco AG, Cundiff GW, Bump RC (2001) Which women with stress incontinence require urodynamic evaluation. Am J Obstet Gynecol 184:20-27

36. Bourcier AP, Juras JC, Villet RM (2004) Office evaluation and physical examination. In: Bourcier AP, McGuire EJ, Abrams (eds) Pelvic floor disorders. Elsevier Saunders, Philadelphia, pp 133148

37. Swift SE, Bent AE (2003) Basic evaluation of the incontinent female patient. In: Bent AE, Ostergard DR, Cundiff GW, Swift SE (eds) Ostegard's urogynecology and pelvic floor dysfunction, 5th edn. Lippincott Williams Wilkins, Philadelphia, pp 69-76

38. Wyman J, Choi S, Hawkins S, Wilson M, Fantl AJ (1988) The urinary diary in evaluation of incontinent women: a test-retest analysis. Obstet Gynecol 71:812-817

39. Elser DM, Fantl JA, McClish DK (1995) Comparison of "subjective" and "objective" measures of severity of urinary incontinence in women. Program for Women Research Group. Neurourol Urodynam 14:311-316

40. Frazer MI, Haylen BT, Sutherst JR (1989) The severity of urinary incontinence in women. Comparison of subjective and objective tests. Br J Urol 63:14-15 
41. Stamey TA (1980) Endoscopic suspension of the vesical neck for urinary incontinence in females. Ann Surg 192:465-471

42. Diokno AC, Brock BM, Brown MB, Herzog AR (1986) Prevalence of urinary incontinence and other urological symptoms in the noninstitutionalized elderly. J Urol 136:1022-1025

43. Jolleys JV (1988) Reported prevalence of urinary incontinence in women in a general practice. BMJ 296:1300-1302

44. Lagace EA, Hansen W, Hickner JM (1993) Prevalence and severity of urinary incontinence in ambulatory adults: an UPRNet study. J Fam Pract 36:610-614

45. Shumacher SA, Wyman JF et al (1994) Health-related quality of life measures for women with urinary incontinence: the incontinence impact questionnaire and the urogenital distress inventory. Qual Life Res 3:291-306

46. Hagen S, Hanley J, Capewell A (2002) Test-retest reliability, validity, and sensitivity to change of the urogenital distress inventory and the incontinence impact questionnaire. Neurourol Urodyn 21:534-539

47. Sandvik H, Hundskaar S et al (1993) Validation of a severity index in female urinary incontinence and its implementation in an epidemiological survey. J Epidemiol Community Health 47:497-499

48. Sandvik H, Selm A et al (2000) A severity index for epidemiological surveys of female urinary incontinence: comparison with 48 hours pad-weighing tests. Neurourol Urodyn 19:137-145

49. Bo K (1994) Reproducibility of instruments designed to measure subjective evaluation of female stress urinary incontinence. Scand J Urol Nephrol 28:97-100

50. Ryhammer AM, Djurhuus JC, Laurberg S (1999) Pad testing in incontinent women: a review. Int Urogynecol J 10:111-115

51. Abrams P, Blaivas JG, Stanton SL, Andersen JT (1988) The standardization of terminology of lower urinary tract function. The International Continence Society Committee on Standardization of Terminology. Scand J Urol Nephrol 114(suppl):5-19

52. Karantanis E, Allen W, Stevermuer TL, Simons AM, O'Sullivan R, More KH (2005) The repeatability of the 24-hour pad test. Int Urogynecol J 16:63-68

53. Tubaro A, Artibani W, Bartram C, Dietz HP, Khullar V, Delancey JD, Zimmern P, Umek W (2005) Pad testing. In: Abrams P, Cardozo L, Khoury S, Wein A (eds) 3rd International Consultation on Incontinence, pp 774-796

54. DuBeau CE, Levy B, Mangione CM, Resnick NM (1998) The impact of urge incontinence on quality of life: Importance of patients' perspective and explanatory style. JAGS 46:683-692

55. Jarvis GJ, Hall S, Stamp S et al (1980) An assessment of urodynamic examination in incontinent women. $\mathrm{Br} \mathrm{J}$ Obset Gynecol 87:893-896

56. Fultz NH, Fisher GG, Jenkins KR (2004) Does urinary incontinence affect middle-aged and older women's time use and activity patterns. Obstet Gynecol 104(6):1327-1334

57. Abrams P, Wein AJ (2002) The impact of Overactive Bladder on Patients and Society, and Current Approaches to Treatment. Institute for Medical Studies CME Activity

58. Verdell L (1999) Consumer Focus'99: a survey. National Association for Continence, Spartanburg South Carolina

59. Heit M, Blackwell L, Ouseph R (2005) Comorbidities affect the impact of urinary incontinence as measured by disease-specific quality of life instruments. Int Urogynecol J 16(1):6-11

60. Ware JE Jr, Sherbourne CD (1992) The MOS 36-item short-form health survey (SF-36). I. Conceptual framework and item selection. Med Care 30(6):473-483

61. Kutner NG, Schechtman KB, Ory MG, Baker DI (1994) Older adults' perceptions of their health and functioning in relation to sleep disturbance, falling, and urinary incontinence. J Am Ger Soc 42(7):757-762
62. Stewart WF, Van Rooyen JB, Cundiff GW, Abrams P, Herzog AR, Corey R, Hunt TL, Wein AJ (2003) Prevalence and burden of overactive bladder in the United States. World J Urol 20(6):327336

63. Avery JC, Gill TK, MacLennan AH, Chittleborough CR, Grant JF, Taylor AW (2004) The impact of incontinence on healthrelated quality of life in a South Australian population sample. Aust N Z J Public Health 28(2):173-179

64. Hagglund D, Walker-Engstrom ML, Larsson G, Leppert J (2004) Changes in urinary incontinence and quality of life after four years. A population-based study of women aged 22-50 years. Scand J Prim Health Care 22(2):112-117

65. Oh SJ, Ku JH (2006) Is a generic QOL instrument helpful for evaluating women with urinary incontinence. Qual Life Res 15:493-501

66. Fitzgerald MP, Kenton K, Shott S, Brubaker L (2001) Responsiveness of quality of life measurements to change after reconstructive pelvic surgery. Am J Obstet Gynecol 185:20-24

67. Lubeck DP, Prebil LA, Peeples P, Brown JS (1999) A healthrelated quality of life measure for use in patients with urge urinary incontinence: a validation study. Qual Life Res 8(4):337344

68. Woodman PJ, Misko CA, Fischer JR (2001) The use of short-form quality of life questionnaires to measure the impact of imipramine on women with urge incontinence. Int Urogynecol J 12(5):312315

69. Barber MD, Walters MD, Bump RC (2005) Short forms of two condition-specific quality of life questionnaires for women with pelvic floor disorders. Am J Obstet Gynecol 193(1):103-113

70. Kelleher CJ, Cardozo LD, Khullar V, Salvatore S (1997) A new questionnaire to assess the quality of life of urinary incontinent women. Br J Obstet Gynaecol 104:1374-1379

71. Reese PR, Pleil AM et al (2003) Multinational study of reliability and validity of the King's Health Questionnaire in patients with overactive bladder. Qual Life Res 12:427-442

72. Kelleher CJ, Kreder KJ, Pleil AM, Burgess SM, Reese PR (2002) Long-term HRQOL of patients receiving extendedrelease tolterodine for OAB. Am J Manag Care 8:S616-S630

73. O'Conor RM, Johannesson M, Hass SL, Kobelt-Nguyen G (1998) Urge incontinence. Quality of life and patients' valuation of symptom reduction. Pharmacoeconomics 14(5):531-539

74. Wren PA, Janz NK, Brubaker L, Fitzgerald MP, Weber AM, LaPorte FB, Wei JT (2005) Reliability of health-related quality of life measures 1 year after surgical procedures for pelvic floor disorders. Am J Obstet Gynecol 192(3):780-788

75. Grimby A, Milstrom I, Molander U (1993) The influence of urinary incontinence on the quality of life in women. Age Ageing 22:82-89

76. Simeonova Z, Milsom I, Kullendorff AM et al (1999) The prevalence of urinary incontinence and its influence on the quality of life in women from an urban Swedish population. Acta Obstet Gynecol Scand 78:546-551

77. Kobelt-Nguyen G, Johanesson M, Mattiasson A et al. Correlations between symptoms of urge incontinence and scores of generic quality of life instruments (SF36) and health status measurements (Euro-Qol) and between changes in symptoms and QoL scores. Abstract: 27th Annual Meeting of international Continence Society, Sept 23-26, 1997, Yokohama, Japan

78. Symonds T (2003) A review of condition-specific instruments to assess the impact of urinary incontinence on health-related quality of life. Eur Urol 43:219-225

79. Matza LS, Zyczynski TM, Bavendam T (2004) A review of quality-of-life questionnaires for urinary incontinence and overactive bladder: which ones to use and why. Curr Urol Rep 5:336342 
80. Kelleher CJ, Cardozo LD (1994) Sexual dysfunction and urinary incontinence. J Sex Health 3:186-191

81. Fultz NH, Herzog AR (2001) Self reported social and emotional impact of urinary incontinence. J Am Geriatr Soc 49:892-899

82. Breakwell SL, Noble Walker S (1988) Differences in physical health, social interaction and personal adjustment between continent and incontinent housebound aged women. J Commun Health Nurs 5:19-31

83. Zorn BH, Montgomery H et al (1999) Urinary Incontinence and depression. J Urol 162:82-84

84. Wagner TH, Patrick DI, Bavendam TG et al (1996) Quality of life in persons with urinary incontinence; development of a new measure. Urology 47:67-72

85. Lee PS, Reid DW, Saltmarche A, Linton L (1995) Measuring the psychosocial impact of urinary incontinence. The York Perceptions Scale (YIPS). J Am Geriatr Soc 43:1275-1278

86. Pauls RN, Segal JL, Silva WA et al (2006) Sexual function in patients presenting to urogynecology practice. Int Urogynecol J 17(6):576-580

87. Whitcomb et al (2006) Are sexual activity and satisfaction impacted by pelvic floor disorders? Neurourol Urodynam

88. Salonia A et al (2004) Sexual dysfunction is common in women with LUTS and UI. Eur Urol 45:642-648

89. Robinson D, Anders K, Cardozo L (2007) Outcome measures in urogynaecology. Int Urogynecol J

90. Mazouni C, Karsenty G, Bretelle F et al (2004) Urinary complications and sexual function after the tension-free vaginal tape procedure. Acta Obstet Gynecol Scand 83 (10):955-961 Oct

91. Ghezzi F, Serati M, Cromi A et al (2006 ) Impact of tension-free vaginal tape on sexual function: results of a prospective study. Int Urogynecol J Pelvic Floor Dysfunct 17(1):54-59 Epub 2005 Jun 23, Jan

92. Utian et al (2005) A methodology study to validate a structured diagnostic method used to diagnoses female sexual dysfunction. J Sex Marital Ther 31:271

93. Jha S, Moran P, Greenham H, Ford C (2007) Sexual function following surgery for urodynamic stress incontinence. Int Urogynecol J 18(8):845-850 Aug

94. Rogers RG, Kammerer-Doak D, Darrow A, Murray K, Olsen A, Barber M, Qualls C (2006) Does sexual function change after surgery for stress urinary incontinence and/or pelvic organ prolapse? A multicenter prospective study. Am J Obstet Gynecol 195(5):1501

95. Crystle CD, Charme LS, Copeland WE (1971) Q-tip test in stress urinary incontinence. Obstet Gynecol 38(2):313-315

96. Karram MM, Bhatia NN (1988) The Q-tip test: standardization of the technique and its interpretation in women with urinary incontinence. Obstet Gynecol 71(6 Pt 1):807-811

97. Pollak JT, Jenkins P, Kopka SL, Davila GW (2003) Effect of genital prolapse on assessment of bladder neck mobility by the Q-tip test. Obstet Gynecol 101(4):662-665

98. Handa VL, Jensen JK, Ostergard DR (1995) The effect of patient position on proximal urethral mobility. Obstet Gynecol 86 (2):273-276

99. Caputo RM, Benson JT (1993) The Q-tip test and urethrovesical junction mobility. Obstet Gynecol 82(6):892-896

100. Schaer GN, Koechli OR, Schuessler B, Haller U (1995) Perineal ultrasound for evaluating the bladder neck in urinary stress incontinence. Obstet Gynecol 85(2):220-224

101. Dietz HP (2004) Ultrasound imaging of the pelvic floor. Part I: two-dimensional aspects. Ultrasound Obstet Gynecol 23(1):80-92

102. Tunn R, Schaer G, Peschers U, Bader W, Gauruder A, Hanzal E et al (2005) Updated recommendations on ultrasonography in urogynecology. Int Urogynecol J 16(3):236-241
103. Dietz HP, Wilson PD (1999) The influence of bladder volume on the position and mobility of the urethrovesical junction. Int Urogynecol J Pelvic Floor Dysfunct 10(1):3-6

104. Peschers UM, Vodusek DB, Fanger G, Schaer GN, DeLancey JO, Schuessler B (2001) Pelvic muscle activity in nulliparous volunteers. Neurourol Urodyn 20(3):269-275

105. Koelbl H, Bernaschek G, Wolf G (1988) A comparative study of perineal ultrasound scanning and urethrocystography in patients with genuine stress incontinence. Arch Gynecol Obstet 244 (1):39-45

106. Bump RC, Mattiasson A, Bo, Brubaker LP, DeLancey JOL, Klarskov P, Shull BL, Smith ARB (1996) The standardization of terminology of female pelvic floor dysfunction. Am J Obstet Gynecol 175:10-17

107. Hall AF, Theofrastous JP, Cundiff GC, Harris RL, Hamilton LF, Swift SE, Bump RC (1996) Interobserver and intraobserver reliability of the proposed International Continence Society, Society of Gynecologic Surgeons, and American Urogynecologic Society Pelvic organ prolapse classification system. Am J Obstet Gynecol 175:1467-1471

108. Kobak WH, Rosenberger K, Walters MD (1996) Interobserver variation in the assessment of pelvic organ prolapse. Int $\mathrm{J}$ Urogynecol Pelvic Floor Dysfunct 7:121-124

109. Athanasiou S, Hill S, Gleeson C, Anders K, Cardozo L (1995) Validation of the ICS proposed pelvic prolapse descriptive system (abstract). Neurourol Urodynam 14:414-415

110. Schussler B, Peschers U (1995) Standardisation of terminology of female genital prolapse according to the new ICS criteria: inter-examiner reliability (abstract). Neurourol Urodynam $14: 437-438$

111. Montella JM, Ewing S, Cater J (1997) Visual assessment of urethrovesical junction mobility. Int Urogynecol J 8(1):13-17

112. Cogan SL, Weber AM, Hammel JP (2002) Is urethral mobility really being assessed by the pelvic organ prolapse quantification (POP-Q) system. Obstet Gynecol 99(3):473-476

113. Noblett K, Lane FL, Driskill CS (2005) Does pelvic organ prolapse quantification exam predict urethral mobility in stages 0 and I prolapse. Int Urogynecol J 16(4):268-271

114. Tapp K, Connolly A, Visco AG (2005) > Evaluation of Aa point and cotton-tipped swab test as predictors of urodynamic stress incontinence. Obstet Gynecol 105(1):115-119

115. Bai SW, Jeon MJ, Kim JY, Chung KA, Kim SK, Park KH (2002) Relationship between stress urinary incontinence and pelvic organ prolapse. Int Urogynecol J 13(4):256-260

116. Richter HE, Burgio KL, Brubaker L et al (2005) Urinary incontinence treatment network. Factors associated with incontinence frequency in a surgical cohort of stress incontinent women. Am J Obstet Gynecol 193(6):2088-2093

117. Linder-Pelz SU (1982) Toward a theory of patient satisfaction. Soc Sci Med 16:577-582

118. Ford RC, Bach SA, Fottler MD (1997) Methods of measuring patient satisfaction in health care organizations. Health Care Manage Rev 22:74-89

119. Lochman JE (1983) Factors related to patients' satisfaction with their medical care. J Community Health 9:91-109

120. Dawn AG, Lee PP (2004) Patient expectations for medical and surgical care: a review of the literature and applications to ophthalmology. Surv Ophthalmol 49:513-524

121. Wilson SJ, Saling MM, Kincade P, Bladin PF (1998) Patient expectations of temporal lobe surgery. Epilepsia 39:167-174

122. Mancuso CA, Salvati EA, Johanson NA, Peterson MG, Charlson ME (1997) Patients' expectations and satisfaction with total hip arthroplasty. J Arthroplasty 12:387-396

123. Feinstein A (1987) Global indexes and scales. In: Gill TM, Feinstein AR (eds) Clinimetrics. Yale University Press, New Haven, CT 
124. Yalcin I, Bump RC (2003) Validation of two global impression questionnaires for incontinence. Am J Obstet Gynecol 189:98-101

125. Guy W (1976) ECDEU assessment manual for psychopharmacology. National Institute of Mental Health, US Department of Health, Education, and Welfare, Rockville, MD

126. Kinchen KS, Obenchain R, Swindle R (2005) Impact of duloxetine on quality of life for women with symptoms of urinary incontinence. Int Urogynecol J 16:337-344

127. Elkadry EA, Kenton KS, FitzGerald MP, Shott S, Brubaker L (2003) Patient-selected goals: a new perspective on surgical outcome. Am J Obstet Gynecol 189:1551-1557 discussion $1557-8$

128. Hullfish KL, Bovbjerg VE, Steers WD (2004) Patient-centered goals for pelvic floor dysfunction surgery: long-term follow-up. Am J Obstet Gynecol 191:201-205

129. Mahajan ST, Elkadry EA, Kenton KS, Shott S, Brubaker L (2006) Patient-centered surgical outcomes: the impact of goal achievement and urge incontinence on patient satisfaction one year after surgery. Am J Obstet Gynecol 194:722-728

130. Abrams P, Cardozo L, Fall M et al (2002) The standardization of terminology of lower urinary tract function: report from the standardization sub-committee of the International Continence Society. Am J Obstet Gynecol 187(1):116-126

131. Cundiff GW, Harris RL, Coates KW, Bump RC (1997) Clinical predictors of urinary incontinence in women. Am J Obstet Gynecol 177(2):262-267

132. Drutz HP, Mandel F (1979) Urodynamic analysis of urinary incontinence symptoms in women. Am J Obstet Gynecol 122:789-792

133. Cardozo LD (1980) Genuine stress incontinence and detrusor instability-a review of 200 patients. Br J Obstet Gynaecol $87: 184-190$

134. Lose G, Griffiths D, Hosker G et al (2002) Standardisation of urethral pressure measurement: report from the standardization sub-committee of the international continence society. Neurourol Urodyn 21:258-260

135. Dmochowski R (1996) Urodynamics 1. Urol Clin North Am 23 (2):243-252

136. Summitt RL, Stovall T, Bent AE, Ostergard DR (1992) Urinary incontinence: correlation of history and brief office evaluation with multichannel urodynamic testing. Am J Obstet Gynecol 166:1835-1844

137. Mortensen S, Lose G, Thyssen H (2002) Repeatability of cystometry and pressure-flow parameters in female patients. Int Urogynecol J 13:72-75

138. Griffiths D (1985) The pressure within a collapsed tube, with special reference to urethral pressure. Phys Med Biol 30(9):951963

139. Rud T (1980) Urethral pressure profile in continence women from childhood to old age. Acta Obstet Gynecol Scand 59:331335

140. Versi E, Cardozo LD, Studd J et al (1986) Evaluation of urethral pressure profilometry for the diagnosis of genuine stress incontinence. World J Urol 4:6-9

141. McGuire EJ (1981) Urodynamic findings in patients after failure of stress incontinence operations. Prog Clin Biol Res 78:351360

142. Appell RA (1998) Primary slings for everyone with genuine stress incontinence? The argument for. Int Urogynecol J 9:249251

143. Leach E, Dmochowski RR, Appell RA et al (1997) Female stress urinary incontinence clinical guidelines panel: report on the surgical management of female stress urinary incontinence. Presented at American Urological Association Female Stress Urinary Incontinence Clinical Guidelines Panel
144. Weber AM (2001) Is urethral pressure profilometry a useful diagnostic test for stress urinary incontinence. Obstet Gynecol Surv 56(11):720-735

145. Sand PK, Winkler H, Blackhurst DW, Culligan PJ (2000) A prospective randomized study comparing modified Burch retropubic urethropexy and suburethral sling for treatment of genuine stress incontinence with low-pressure urethra. Am J Obstet Gynecol 182(1 Pt 1):30-34 Jan

146. Vereecken RL, Proesmans W (2000) Urethral instability as an important element of dysfunctional voiding. U Urol 163(2):585$588 \mathrm{Feb}$

147. McGuire EJ, Woodside JR, Borden TA et al (1981) Prognostic value of urodynamic testing in myelodysplastic patients. J Urol $126: 205$

148. Lane TM, Shah PJR (2000) Leak-point pressures. BJU International 86:942-949

149. Bump RC, Hurt GW, Theofrastous JP et al (1996) The Continence Program for Women Research Group. Randomized prospective comparison of needle colposuspension versus endopelvic fascia plication for potential stress incontinence prophylaxis in women undergoing vaginal reconstruction for stage III or IV pelvic organ prolapse. Am J Obstet Gynecol 175 (2):326-335

150. Richardson DA, Bent AE, Ostergard DR (1983) The effect of uterovaginal prolapse on urethrovesical pressure dynamics. Am J Obstet Gynecol 146:901-905

151. Romanzi LJ, Chaikin DC, Blaivas JG (1999) The effect of genital prolapse on voiding. J Urol 161:581-586

152. Mattox TF, Bhatia NN (1994) Urodynamic effects of reducing devices in women with genital prolapse. Int Urogynecol J 5:283286

153. Bhatia NN, Bergman A, Gunning JE (1983) Urodynamic effects of a vaginal pessary in women with stress urinary incontinence. Am J Obstet Gynecol 147:876-884

154. Bump RC, Fantl JA, Hurt WG (1988) The mechanism of urinary continence in women with severe uterovaginal prolapse: results of barrier studies. Obstet Gynecol 72:291-295

155. Agency for Health Care Policy and Research Public Health Service, US Department of Health and Human. March (1996) Urinary incontinence guideline panel. Urinary incontinence in adults: clinical practice guideline. AHCRP Pub no. 92-038. Rockville, MD

156. Handa VL, Jensen JK, Ostergard DR (1995) Federal guidelines for the management of urinary incontinence in the united states: which patients should undergo Urodynamic testing. Int J Gynecol Obstet 6:198-203 15

157. Videla F, Wall LL (1998) Stress incontinence diagnosed without multichannel urodynamic studies. Obstet Gynecol 91:965-968

158. Diokno AC, Dimaculangan RR, Lim BU, Steinert BW (1999) Office based criteria for predicting type II stress incontinence without further evaluation studies. J Urol 161:1263-1267

159. Lemack GE, Zimmern PE (2000) Identifying patients who require urodynamic testing before surgery for stress incontinence based on questionnaire information and surgical history. Urology 55:506-511

160. Jensen JK, Nielsen R, Ostergard DR (1994) The role of patient history in the diagnosis of urinary incontinence. Obstet Gynecol 83(5):904-910

161. Homma Y, Batista J, Bauer S et al (2002) Urodynamics. In: Abrams P, Cardozo L, Khoury S et al (eds) Incontinence: 2nd International Consultation on Incontinence. Plymouth, United Kingdom, p 317

162. Moolgaoker AS, Ardran GM, Smith JC, Stallworthy JA (1972) The diagnosis and management of urinary incontinence in the female. J Obstet Gynaecol Br Commonw 79:481-497 
163. Massey A, Abrams P (1985) Urodynamics of the female lower urinary tract. Urol Clin North Am 12:231-246

164. Thompson PD, Duff DS, Thayer PS (2000) Stress incontinence in women under 50: does urodynamics improve surgical outcome. Int Urogynecol J 11:285-289

165. Glazener CM, Lapitan MC (2002) Urodynamic investigations for management of urinary incontinence in adults. Cochrane Database Syst Rev 3:CD003195

166. Homma Y (2002) The clinical significance of the urodynamic investigation in incontinence. BJU Int 90(5):489-497

167. McLennan MT, Melick CF, Bent AE (1998) Clinical and urodynamic predictors of delayed voiding after fascia lata suburethral sling. Obstet Gynecol 92:608-612

168. Litwiller SE, Nelson RS, Fone PD, Kim KB, Stone R (1997) Vaginal wall sling: long-term outcome analysis of factors contributing to patient's satisfaction and surgical success. J Urol 157:1279-1282

169. Weber AM, Walters MD (2000) Cost-effectiveness of urodynamic testing before surgery for women with pelvic organ prolapse and stress urinary incontinence. Am J Obstet Gynecol 183:1338-1347

170. Snooks SJ, Badenoch DF, Tiptaft RC, Swash M (1985) Perineal nerve damage in genuine stress urinary incontinence. An electrophysiological study. . Br J Urol 57(4):422-426

171. Snooks SJ, Barnes PR, Swash M (1984) Damage to the innervation of the voluntary anal and periurethral sphincter musculature in incontinence: an electrophysiological study. J Neurol Neurosurg Psychiatry 47(12):1269-1273

172. Snooks SJ, Henry MM, Swash M (1985) Fecal incontinence due to external anal sphincter division in childbirth is associated with damage to the innervation of the pelvic floor musculature: a double pathology. Br J Obstet Gynaecol 92(8):824-828

173. Snooks SJ, Swash M, Henry MM, Setchell M (1986) Risk factors in childbirth causing damage to the pelvic floor innervation. Int J Colorectal Dis 1(1):20-24

174. Snooks SJ, Swash M, Mathers SE, Henry MM (1990) Effect of vaginal delivery on the pelvic floor: a 5-year follow-up. Br J Surg 77(12):1358-1360

175. Benson J (1998) Pelvic floor neurophysiology. American Association of Electrodiagnostic Medicine, Rochester, MN

176. Zivkovic M (1996) Quantitative and qualitative scores on dream test. Percept Mot Skills 83(3 Pt 1):867-880

177. Chen AS, Luchtefeld MA, Senagore AJ, Mackeigan JM, Hoyt C (1998) Pudendal nerve latency. Does it predict outcome of anal sphincter repair. Dis Colon Rectum 41(8):1005-1009

178. Gilliland R, Altomare DF, Moreira H Jr et al (1998) Pudendal neuropathy is predictive of failure following anterior overlapping sphincteroplasty. Dis Colon Rectum 41(12):1516-1522

179. Sangwan YP, Coller JA, Barrett RC et al (1996) Prospective comparative study of abnormal distal rectoanal excitatory reflex, pudendal nerve terminal motor latency, and single fiber density as markers of pudendal neuropathy. Dis Colon Rectum 39 (7):794-798

180. Sethi RK, Bauer SB, Dyro FM, Krarup C (1989) Modulation of the bulbocavernosus reflex during voiding: loss of inhibition in upper motor neuron lesions. Muscle Nerve 12(11):892-897

181. Mahajan ST, Fitzgerald MP, Kenton K, Shott S, Brubaker L (2006) Concentric needle electrodes are superior to perineal surface-patch electrodes for electromyographic documentation of urethral sphincter relaxation during voiding. BJU International 97(1):117-120

182. Fowler CJ (2003) Urinary retention in women. BJU Int 91 (6):463-464

183. Allen RE, Hosker GL, Smith AR, Warrell DW (1990) Pelvic floor damage and childbirth: a neurophysiological study. Br J Obstet Gynaecol 97(9):770-779
184. Gregory WT, Lou JS, Stuyvesant A, Clark AL (2004) Quantitative electromyography of the anal sphincter after uncomplicated vaginal delivery. Obstet Gynecol 104(2):327-335

185. Weidner AC, Sanders DB, Nandedkar SD, Bump RC (2000) Quantitative electromyographic analysis of levator ani and external anal sphincter muscles of nulliparous women. Am J Obstet Gynecol Nov 183(5):1249-1256

186. Aanestad O, Flink R (1999) Urinary stress incontinence. A urodynamic and quantitative electromyographic study of the perineal muscles. Acta Obstet Gynecol Scand 78(3):245-253

187. Fisher JR, Hale D, McClellan E, Benson JT (2001) The use of urethral electrodiagnosis to select the method of surgery in women with intrinsic sphincter deficiency. Int Urogynecol J 12 (Suppl 1):51

188. Kenton K, FitzGerald MP, Shott S, Brubaker L (2001) Role of urethral electromyography in predicting outcome of Burch retropubic urethropexy. Am J Obstet Gynecol 185(1):51-55

189. European Confederation of Laboratory Medicine (2000) European urinalysis guidelines. Scand J Clin Lab Invest, Suppl 231:1-86

190. Benson JT, McClellan E (1993) The effect of vaginal dissection on the pudendal nerve. Obstet Gynecol 82(3):387-389

191. Welgoss JA, Vogt VY, McClellan EJ, Benson JT (1999) Relationship between surgically induced neuropathy and outcome of pelvic organ prolapse surgery. Int Urogynecol J 10(1):11-14

192. Maher CF, Qatawneh AM, Dwyer PL et al (2004) Abdominal sacral colpopexy or vaginal sacrospinous colpopexy for vaginal vault prolapse: a prospective randomized study. Am J Obstet Gynecol 190(1):20-26

193. Petri E (1999) Urologic trauma in gynaecological surgery: diagnosis and management. Curr Opin Obstet Gynaecol 11 (5):495-498

194. Rosen DM, Korda AR, Waugh RC (1996) Ureteric injury at Burch colposuspension. 4 case reports and literature review. Anst N Z J Obstet Gynaecol 36(3):354-358

195. Delaere KP, Strijbos WE, Zandvoort JA (1989) Perirenal urinary extravasation complicating Burch colposuspension. Urol Int 44 (2): $119-120$

196. Minervini A, Salinitri G, Minervini R (2003) Retroperitoneal urinoma complicating Burch colposuspension. Int J Gynaecol Obstet 82(1):85-86

197. Flores Rosas SA, Cabrera Jacome R, Galeano Portillo A (2004) Ureteral obstruction: an infrequent complication of Burch colposuspension. Report of 2 cases. Ginecol Obstet Mex 72 (1):39-44

198. Speights SE, Moore RD, Miklos JR (2000) Frequency of lower urinary tract injury at laparoscopic Burch and paravaginal repair. J Am Assoc Gynecol Laparosc 7(4):515-518

199. Dwyer PL, Carey MP, Rosamilia A (1999) Suture injury to the urinary tract in urethral suspension procedures for stress incontinence. Int Urogynecol J 10(1):15-21

200. Stevenson KR, Cholhan HJ, Hartmann DM, Buchsbaun GM, Guzick DS (1999) Lower urinary tract injury during the Burch procedure: is there a role for routine cystoscopy. Am J Obstet Gynecol 181(1):35-38

201. Demirci F, Yucel N, Ozden S, Delikara N, Yalti S, Demirci E (1999) A retrospective review of perioperative complications in 360 patients who had Burch colposuspension. Aust N Z J Obstet Gynaecol 39(4):472-475

202. Kenton K, Oldham L, Brubaker L (2002) Open Burch urethropexy has a low rate of perioperative complications. Am J Obstet Gynecol 187(1):107-110

203. Paraiso MF, Walters MD, Karram MM, Barber MD (2005) Laparoscopic burch colposuspension versus tension-free vaginal tape: a randomized trial. Obstet Gynecol Surv 60(3):166-167

204. Bhatia NN, Bergman A (1984) Urodynamic predictability of voiding following incontinence surgery. Obstet Gynecol 51:204 
205. Juma S, Brito CG (2007) Transobturator tape (TOT): two years follow-up. Neurourol Urodyn 26(1):37-41

206. Botros SM, Miller JJ, Goldberg RP, Gandhi S, Akl M, Beaumont JL, Sand PK (2007) Detrusor overactivity and urge urinary incontinence following transobturator versus midurethral slings. Neurourol Urodyn 26(1):42-45

207. Vervest HA, Bisseling TM, Heintz AP, Schraffordt Koops SE (2007) The prevalence of voiding difficulty after TVT, its impact on quality of life, and related risk factors. Int Urogynecol J Pelvic Floor Dysfunct 18(2):173-182 Feb

208. Bezerra CA, Bruschini H (2001) Suburethral sling operations for urinary incontinence in women. Cochrane Database Syst Rev 3: CD001754

209. Stanford EJ, Levy B, Rosenblatt P (2005) The use of mesh in pelvic reconstructive surgery. OBG Management, April

210. Deng DY, Rutman M, Raz S, Rodriguez LV (2007) Presentation and management of major complications of midurethral slings: Are complications under-reported. Neurourol Urodyn 26(1):4652 Supplement

211. Bhatia NN, Bergman A (1985) Modified Burch versus Pereyra retropubic urethropexy for stress urinary incontinence. Obstet Gynecol 66:255-261

212. Bergman A, Elia G (1985) Three surgical procedures for genuine stress incontinence: five-year follow-up of a prospective randomized study. Am J Obstet Gynecol 173(1):66$71 \mathrm{Jul}$

213. Schostak M, Jeicappel R, Muller M et al (2001) Minimally invasive bone anchor in therapy of female stress incontinence. A good concept. Urologe A 40(2):107-113

214. Comiter CV, Colegrove PM (2004) High rate of vaginal extrusion of silicone-coated polyester sling. Urology 63 (6): 1066-1070

215. Palma P, Riccetto C, Herrmann V et al (2005) Transobturator SAFYRE sling is as effective as the transvaginal procedure. Int Urogynecol J 16(6):487

216. Nilsson CG (2002) TVT complication prevention and management. Int Cont Soc. Heidelberg 28.-30.8

217. Kuno K, Menzin A, Kauder HH, Sison C, Gal D (1998) Prophylactic ureteral catheterization in gynecologic surgery. Urology 52(6):1004-1008
218. Petri E, Niemeyer R, Thielemann F, Bub P (1998) Ureteral lesions during gynecologic surgery. 23rd Annual Meeting of the International Urogynecological Association (IUGA): Abstracts. Int Urogynecol J 9:330

219. Cutler DM (1995) The cost and financing of health care. Am Econ Rev 85:32-37

220. Gold MR, Siegel JE, Russell LB, Weinstein MC (eds) (1996) Cost-effectiveness in health and medicine. Oxford University Press, Oxford

221. Fein R (1958) Economics of mental health. Basic Books, New York

222. Johannesson M, O'Connor RM, Kobelt-Nguyen G, Mattiasson A (1997) Willingness to pay for reduced incontinence symptoms. Br J Urol 80:557-562

223. Murray CJ, Lopez AD (1996) Evidence-based health policy-lessons from the Global Burden of Disease Study. Science 274:740-743

224. Muray CJ, Lopez AD (1997) The global burden of disease: a comprehensive assessment of mortality and disability from diseases, injuries and risk factors in 1990 and projected to 2020. Harvard University Press, Cambridge, MA

225. Torrance G (1986) Measurement of health state utilities for economic appraisal: a review. J Health Econ 5:1-30

226. Brazier J, Deverill M, Green C, Harper R, Booth A (1999) A review of the use of health status measures in economic evaluation. Health Technol Assess 3:1-165

227. Bennett KG, Torrance GW (1996) Measuring health state preferences and utilities: rating scale, time trade-off, and standard gamble techniques. Quality of life and pharmacoeconomics in clinical trials. Lippincott-Raven, Philadelphia

228. Robinson A, Dolan P, Williams A (1997) Valuing health states using VAS and TTO: what lies behind the numbers. Soc Sci Med 45:1289-1297

229. Dumville JC, Manca A, Kitchener HC, Smith ARB, Nelson L, Torgerson DJ, on behalf of the COLPO study group (2006) Costeffectiveness analysis of open colposuspension versus laparoscopic colposuspension in the treatment of urodynamic stress incontinence. BJOG 113(9):1014-1022

230. Manca A, Sculpher MJ, Ward KL, Hilton P (2003) A cost-utility analysis of tension-free vaginal tape versus colposuspension for primary urodynamic stress incontinence. Br J Obstet Gynaecol 110(3):255-262 